Illinois State University

ISU ReD: Research and eData

Theses and Dissertations

$5-25-2016$

\title{
Examining The Application Of Experiential Learning Techniques Across Sport Management Programs
}

Elizabeth Sattler

Illinois State University, holcomb.elizabeth@gmail.com

Follow this and additional works at: https://ir.library.illinoisstate.edu/etd

Part of the Curriculum and Instruction Commons, Higher Education Administration Commons, Higher Education and Teaching Commons, and the Sports Management Commons

\section{Recommended Citation}

Sattler, Elizabeth, "Examining The Application Of Experiential Learning Techniques Across Sport Management Programs" (2016). Theses and Dissertations. 597.

https://ir.library.illinoisstate.edu/etd/597

This Dissertation is brought to you for free and open access by ISU ReD: Research and eData. It has been accepted for inclusion in Theses and Dissertations by an authorized administrator of ISU ReD: Research and eData. For more information, please contact ISUReD@ilstu.edu. 


\title{
EXAMINING THE APPLICATION OF EXPERIENTIAL LEARNING TECHNIQUES ACROSS SPORT MANAGEMENT PROGRAMS
}

\author{
Elizabeth A. Sattler
}

\section{Pages}

The Commission on Sport Management Accreditation (COSMA) has identified experiential learning projects as an integral element to be included in sport management curriculum (COSMA, 2016). However, often the experiential learning opportunities offered by sport management programs are limited to a required internship experience (Foster \& Dollar, 2010). While internship programs have been widely accepted and implemented by sport management programs (Eagleman \& McNary, 2010), there is little evidence of the implementation of other experiential learning practices within sport management programs. Consequently, the purpose of this study was to investigate the widespread application of experiential learning practices of sport management faculty. Using Foster and Dollar's (2010) Five-Step Experiential Learning Process Model (Foster \& Dollar, 2010), a survey instrument was adapted and sent to all subscribers to the North American Society for Sport Management (NASSM) List-serv. A total of 136 electronic surveys were completed by faculty and considered usable for analysis, resulting in a $16.6 \%$ response rate. 
Results showed that the overwhelming majority of sport management faculty are utilizing some form of experiential learning both inside and outside of the classroom. Particularly, a large percentage of faculty identified as "Adopters" of both classroombased experiential learning and internship experiences. While usage rates were high for those techniques, usage rates were considerably lower for techniques like volunteer exploration, practicum elective, and apprenticeship. Faculty held favorable attitudes towards experiential learning as a practice, particularly in its ability to help students engage with local sport organizations and businesses. Finally, more in depth analysis revealed some significant group differences based on the terminal degree program and the course teaching load of faculty.

KEYWORDS: Sport, Management, Experiential, Learning, Curriculum, Education 


\section{EXAMINING THE APPLICATION OF EXPERIENTIAL LEARNING \\ TECHNIQUES ACROSS SPORT MANAGEMENT PROGRAMS}

ELIZABETH A. SATTLER

A Dissertation Submitted in Partial

Fulfillment of the Requirements for the Degree of

DOCTOR OF EDUCATION

School of Teaching and Learning

ILLINOIS STATE UNIVERSITY

2016 
Copyright 2016 Elizabeth A. Sattler 
EXAMINING THE APPLICATION OF EXPERIENTIAL LEARNING

\section{TECHNIQUES ACROSS SPORT MANAGEMENT PROGRAMS}

ELIZABETH A. SATTLER

COMMITTEE MEMBERS:

Thomas P. Crumpler, Chair

Alan Bates

Gary Weilbacher

Clinton Warren 


\section{ACKNOWLEDGMENTS}

I would like to first thank my dissertation committee for their unrelenting guidance and support throughout this journey. A special thank you goes out to Dr. Thomas Crumpler for his willingness to take on the added responsibilities as chair of the committee. Sincere thanks are also given to Dr. Clinton Warren and Dr. Alan Bates for their methodological and statistical expertise, and Dr. Gary Weilbacher for his keen editing eye and critical analysis.

Sincere gratitude goes out to my mentors, Dr. Chad McEvoy and Dr. Nels Popp, who helped me view the sport industry in a new light, encouraged me to pursue a doctoral degree, and showed me the ropes as a young educator. I am so grateful for your continued support, and friendship.

I know that none of this would be possible if it weren't for the constant encouragement and support of my parents, Tony and Rose Holcomb. Dad, you instilled a love of sport in me at a young age. You taught me that hard work pays off and that at the end of the day, trying your best is all that matters. Mom, you've been my number one supporter since day one. Whether it was driving me around to sports practices or helping me with homework, you were always there when I needed you.

Finally, I want to thank my husband, Mike Sattler, for his unwavering support and patience during this process. I am forever grateful for your love and friendship.

E. A. S. 


\section{CONTENTS}

Page

ACKNOWLEDGMENTS $\quad$ i

$\begin{array}{ll}\text { CONTENTS } & \text { ii }\end{array}$

TABLES

CHAPTER

I. THE PROBLEM AND ITS BACKGROUND 1

Introduction 1

Statement of the Problem $\quad 5$

Theoretical Framework: Experiential Learning Theory 7

Research Questions 11

Definition of Terms $\quad 12$

$\begin{array}{ll}\text { Significance of the Study } & 14\end{array}$

II. REVIEW OF LITERATURE 16

$\begin{array}{ll}\text { Overview } & 16\end{array}$

The History and Evolution of Sport Management Pedagogy 16

Experiential Learning Practices in Higher Education 22

Experiential Learning in Sport Management Academia 30

III. METHODOLOGY 39

Research Questions $\quad 39$

Hypotheses $\quad 40$

Research Design $\quad 40$

Data Collection Procedures $\quad 41$

Instrumentation $\quad 42$

Study Variables $\quad 45$

Validity and Reliability $\quad 46$

Data Analysis $\quad 47$ 
$\begin{array}{lr}\text { IV. RESULTS } & 50\end{array}$

Analysis of Data $\quad 50$

Demographic Profile $\quad 51$

Findings and Results $\quad 54$

RQ1: Faculty Usage of Experiential Learning Techniques 54

RQ2: Faculty Attitudes Towards Experiential Learning 57

RQ3: Impact of Academic and Professional Experience on Faculty Attitudes Towards Experiential Learning 62

$\begin{array}{ll}\text { Summary } & 72\end{array}$

V. SUMMARY, CONCLUSIONS, AND

$\begin{array}{ll}\text { RECOMMENDATIONS } & 73\end{array}$

Summary of the Research $\quad 73$

Research Questions $\quad 75$

$\begin{array}{ll}\text { Hypotheses } & 75\end{array}$

$\begin{array}{ll}\text { Conclusions } & 77\end{array}$

RQ1: Faculty Usage of Experiential Learning Techniques $\quad 78$

RQ2: Faculty Attitudes Towards Experiential Learning 82

RQ3: Impact of Academic and Professional Experience on Faculty Attitudes Towards Experiential Learning 86

Significance of the Study $\quad 91$

Limitations of the Study $\quad 94$

Future Research Questions 96

$\begin{array}{ll}\text { REFERENCES } & 100\end{array}$

$\begin{array}{ll}\text { APPENDIX A: } & \text { Permission to Modify Service Learning in } \\ & \text { Marketing Curriculum Survey }\end{array}$

$\begin{array}{ll}\text { APPENDIX B: } & \text { E-mail Communication to NASSM Listserv to } \\ & \text { Request Participation }\end{array}$

$\begin{array}{ll}\text { APPENDIX C: } & \begin{array}{l}\text { Experiential Learning in Sport Management } \\ \text { (ELSM) Survey Instrument }\end{array}\end{array}$

APPENDIX D: Institutional Review Board Approval $\quad 122$ 


\section{TABLES}

Table

Page

1. Foster and Dollar's (2010) Five-Step Experiential Learning Process Model

2. Andreasen's (1995) Stages of Behavior Change 44

3. Comparison of Survey Items for ELSM Survey (Section 3) 44

4. Experiential Learning in Sport Management (ELSM) Study Variables 46

5. Respondent Characteristics 53

6. Faculty Usage of Experiential Learning Techniques 56

7. Most Effective Experiential Learning Technique 59

8. Faculty Attitudes Towards Experiential Learning 60

9. One-Way Analysis of Variance of Attitudes Towards Experiential Learning by Terminal Degree Program 65

10. Bonferroni Test for Group Differences by Terminal Degree Program 66

11. One-Way Analysis of Variance of Attitudes Towards Experiential Learning by Years of Sport Industry Experience

12. Independent Samples t-test for Faculty Attitudes and Course Teaching Experience

13. Independent Samples t-test for Faculty Attitudes and Course Teaching Load 


\section{CHAPTER I}

\section{THE PROBLEM AND ITS BACKGROUND \\ Introduction}

The United States sport industry has grown into an estimated $\$ 60.5$ billion dollar industry, with a compound annual growth rate of 5.1\% (Heitner, 2015). Pitts and Stotlar (2007) define the sport industry as "the market in which the products offered to its buyers are sport, fitness, recreation, or leisure-related and may be activities, goods, services, people, places, or ideas" (p. 3). Segments of the sport industry include: tourism, amateur participant sports, professional sports, recreation, high school and college sports, outdoor sports, sporting goods and apparel, sport marketing firms, sport sponsorship management companies, and sport governing bodies (Pitts \& Stotlar, 2007).

Due to the immense growth of the sport industry in recent decades, the popularity of the sport management major has skyrocketed. The number of institutions offering undergraduate sport management degrees has grown from just 20 programs in 1980 (Mahony \& Pitts, 1998) to over 300 undergraduate programs in colleges and universities in the United States today (NASSM, 2016). Traditionally, student learning in undergraduate sport management courses has been centered on textbooks or academic readings and subject information was communicated through lectures and in-class discussions (Spence, Hess, McDonald, \& Sheehan, 2009). While sport management 
curricula has evolved significantly over the last decade to include more applied learning opportunities for students (COSMA, 2016), there are still questions regarding the core mission of a sport management education. From its early stages to present day, scholars within the field of sport management have often debated the core mission of its academic programs. Is the goal to prepare students for careers within a business-oriented sport industry or for careers focused on physical education, health, and sport for development? Is sport management education a combination of both? Should the research scholars conduct be concerned with sport industry practitioners and the problems they face or should that focus be on theory development, or both? What courses will best prepare sport management students to meet the demands of the competitive sport industry and to be passionate, democratic members of society? Answers to these questions provide insight into the issues that have and continue to impact the field, and the discussions surrounding such questions have helped to shape the current landscape of sport management academia today.

In a seminal piece of literature published in the Journal of Sport Management $(J S M)$, a leading journal in the field of sport management, Weese (1995) asked fellow sport management scholars to question who they were serving in their daily practice as scholars. Did they do their best to serve students, scholars, and practitioners in the field? His central question surrounded the stakeholder group of sport practitioners working in the field, and whether or not members of the North American Association for Sport Management (NASSM) and authors of the Journal of Sport Management (JSM), were doing enough to serve practitioners in the industry. He argued that sport management scholarship failed to serve this important stakeholder group, and therefore, struggled to 
truly have an impact on the sport management profession. He offers parallel examples from the fields of management and leadership, scholarly areas that also at one time lacked practical application to their respective fields. Mintzberg (1982), a management scientist once suggested that "when researchers can only talk to each other, then they ultimately serve nobody" (p. 240). Weese echoes this sentiment in his call for leaders in sport management academia to work to bridge the gap between scholars and practitioners. The failure to do so, he suggests, limits the scholarly potential to contribute to the sport management community as a whole. In concluding his analysis, Weese states that in order to serve all constituents, the underlying vision for the sport management field moving forward should consider both theoretical and applied aspects of sport management, with a particular focus on including the practitioner in the on-going dialogue about the state of sport management. His mission was not to squash the theoretical focus of the field, but to open up a line of communication with those serving as practitioners in the field. He believed that this shift would lead to a more meaningful dialogue for all constituents within the field of sport management. And perhaps most importantly, that this dialogue would cultivate an interdisciplinary approach to educating future sport managers.

While Weese's sentiment was applauded by many in the field, not all agreed with his push towards a more applied field. In their response to Weese's editorial, Cuneen and Parks (1997) argued that in order for the field of sport management to maintain its standing in the academic community, it had to continue to operate in a theoretical, scholarly framework. They argued that NASSM and JSM had "naturally evolved" to meet the needs of sport management education, and that they had already succeeded in 
serving the sport management professoriate, student-scholars, and practitioners "who seek a symbiotic relationship with the academy" (p. 125). They believed the absence of sport practitioners within NASSM had little to do with a lack of perceived value, but rather, that those practitioners had a multitude of practitioner-oriented organizations to belong to, and therefore had a limited amount of resources and time to devote to NASSM. Cuneen and Parks (1997) argued that the purpose of NASSM should remain focused on the academy, and that its members already contributed to the industry through exchanging research output with one another, as well as their preparation of students to work in the field.

Nearly twenty years have passed since Weese (1995) and Cuneen and Parks (1997) debated the core mission of NASSM and JSM. While a great deal of progress has been made to validate and establish this academic area since that time, to this day scholars often still dispute the core mission of a sport management education. While some scholars in the field of sport management appear to have moved towards a more applied approach to curriculum development and delivery, others have criticized the shift. A concern is that sport management programs have become too focused on the bottom line, business functions of sport organizations and now fail to provide students with critical, thought-provoking, social and political dialogue in the classroom (Amis \& Silk, 2005; Frisby, 2005; Zakus, Malloy, \& Edwards, 2007). In a more recent response to Weese's (1995) call to action, and to the changing landscape of sport management pedagogy, Newman (2014) argued that sport management scholars have "given their research and teaching over to assumptions and promulgations of sport as industry, the athlete as commodity, the team as brand, the fan as consumer, and the sport facilitator as 
manager" (p. 604). He calls for a shift away from the current, market-driven focus of sport management, back towards the once society-driven field unfocused on the business element of the sport industry. On the other hand, others in the field continue to echo Weese's sentiment by calling for more applied and practical learning within sport management programs. In their discussion of partnerships between intercollegiate athletic departments and sport management academic programs, Popp and McEvoy (2010) suggest that both students and practitioners can benefit from applied learning opportunities outside of the classroom. Even 20 years after Weese's initial call-to-action, the debate over the core mission of sport management education continues on.

\section{Statement of the Problem}

Over the last decade, there has been a dramatic increase in the amount of scholarly work addressing sport management pedagogy, thanks in part to the creation of the Sport Management Education Journal (SMEJ) in 2007. Much of the work published in $S M E J$ since its inception has addressed practical and experiential learning in the classroom, a further reflection of the move towards a more applied approach to delivering sport management curricula in recent years. Evidence of a move towards a more experiential curricula can be seen by comparing a 1990 analysis (Desensi, Kelly, Blanton, $\&$ Beitel, 1990) of sport management programs that found $63 \%$ of programs required an internship experience to a more recent study (Eagleman \& McNary, 2010) that found that nearly $80 \%$ of programs now require an internship experience. In addition, the Commission on Sport Management Accreditation (COSMA) has identified experiential learning projects as an integral element to be included in sport management curriculum 
(COSMA, 2016), and a handful of sport management educators have embraced the concept, as evidenced through the publication of various experiential learning models.

Although there is evidence that the majority of sport management programs now require an internship experience of their students (Eagleman \& McNary, 2010), there is little information regarding the implementation of other experiential learning practices within sport management programs. While some sport management educators have moved towards a more experiential, applied learning model within sport management classrooms, the extent to which academics across the field of sport management are applying these same techniques is unclear. And while a handful of sport management scholars have examined experiential learning outcomes within individual classroom environments (Irwin, Sutton, \& McCarty, 2007; Pauline, 2013; Southall, Nagel, LeGrande, and Han, 2003), a singular study has yet to provide an in-depth analysis of the widespread application of experiential learning practices across the field of sport management. In addition, no studies have examined sport management faculty attitudes towards the use of experiential learning practices and their impact on student learning.

As previously discussed, the field remains divided in many ways when it comes to determining whether the core mission of a sport management education is theoretical or applied in nature. Studying the implementation of experiential learning tactics may provide further insight into the current view of those in the field. In addition, a growing desire for more experiential education in institutions of higher education continues to grow, as millennial students have come to expect an engaging and interactive learning environment (Mangold, 2007). As this growth continues, it is important to determine the extent to which faculty within sport management apply experiential practices both inside 
and outside of the classroom. Therefore, the purpose of this study is three-fold.

Specifically, this study investigates the application of experiential learning practices across sport management programs. Additionally, this study seeks to examine faculty attitudes as they relate to the application of experiential learning practices and their impact on student learning. Finally, this study seeks to determine the impact of academic and professional experiences on faculty attitudes towards the implementation of experiential learning techniques.

\section{Theoretical Framework: Experiential Learning Theory}

This study will be situated within an experiential learning theory framework based on Kolb's (1984) experiential learning theory (ELT). In experiential learning, students gain knowledge through observation and interaction with situations or experiences, as opposed to traditional learning, where students learn through reading, lecture, and/or testing (Itin, 1999). Much like the educational theorists who came before him, Kolb's theory is based on a holistic model of learning that is derived from one's own experiences (Kolb \& Kolb, 2009). Because this particular study looks to analyze the implementation of experiential learning practices across sport management programs, it is necessary to view it through experiential learning theory.

From John Dewey (1916) to Carl Rogers (1983), a number of preeminent scholars throughout history have argued for the implementation of experiential learning across all levels of education. Dewey was one of the first to recognize that learning should be considered a process and not simply a system based on outcomes. As a strong proponent of experiential learning, he believed the traditional authoritarian form of educating lacked the necessary experiential factor, and in turn, failed to develop successful, democratic 
members of society (Dewey, 1916). In regards to his experiential philosophy to education, Dewey (1916) once stated, "Give the pupils something to do, not something to learn; and the doing is of such a nature as to demand thinking; learning naturally results" (p. 181). For the handful of scholars within sport management that have implemented and studied experiential learning frameworks into their courses (Pauline \& Pauline, 2008; McKeylvey \& Southall, 2008; Pierce, Petersen, \& Meadows, 2011) it is evident that student learning outcomes do tend to be positively impacted, as Dewey had long suggested they would be.

Dewey's philosophy towards educating the youth of America was also a democratic one. He viewed schools as unnatural settings for learning and he saw the modern school as a building of repression and confinement that failed to provide America's youth with a democratic education that would lead to their success as adults (Benson, Harkavy, \& Puckett, 2007). Dewey saw education as having a broader social purpose, which was to help people become more effective members of a democratic society. He argued that the one-way delivery style of authoritarian schooling did not provide a good model for life in democratic society, but instead, promoted educational experiences that could enable them to become valued, responsible members of society (Kliebard, 2004).

In his 1983 book, Freedom to Learn for the 80s, Carl Rogers described his belief in the importance of experiential learning:

The only man who is educated is the man who has learned how to adapt and change; the man who has realized that no knowledge is secure, that only the process of seeking knowledge gives a basis for security. Changingness, reliance 
on process rather than upon static knowledge, is the only thing that makes any sense as a goal for education in the modern world (p.104).

Rogers realized the importance of an experiential learning model for student success in the modern world. His belief is echoed by modern scholars, as many across academia have called for pedagogy that encourages students to engage beyond the traditional mode of learning to a more experiential model (McManus, 2005).

Both Dewey and Rogers identified that learning occurred most when students were provided opportunities to do and act, as well as when they were provided opportunities to reflect and change. They agreed that at the heart of experiential learning was the student, and their own unique experiences. In addition, the basis for experiential learning theory according to Dewey, Rogers, and also Kolb, is a constructivist base, which lends itself to a model or in Kolb's case, a cycle for explaining how students learn through experiential learning theory (Kolb \& Kolb, 2008). Kolb's (2009) model for experiential learning theory expands on the concepts previously developed by his predecessors and goes one step further by providing a four-step activity model to further describe the process of experiential learning. The experiential learning theory (ELT) model represents two related modes of grasping experience - Concrete Experience (CE) and Abstract Conceptualization (AC), and two related modes of transforming experience - Reflective Observation (RO) and Active Experimentation (AE) (Kolb \& Kolb, 2009). In the first stage, Kolb suggests that individuals acquire information through their own lived experiences (i.e. Concrete Experience (CE). Next, he suggests that learners must reflect on those lived experiences through some form of reflective exercise (i.e. 
Reflective Observation (RO). In the next stage, Kolb suggests that learners can revise their model of thinking based on their new observations through lived experiences. In other words, people can learn from their experience (i.e. Abstract Conceptualization (AC). Finally, Kolb suggests that individuals can then transform their behavior by testing their newly developed theories through experimentation (i.e. Active Experimentation). "This process is portrayed as an idealized learning cycle or spiral where the learner "touches all bases" - experiencing, reflecting, thinking, and acting - in a recursive process that is responsive to the learning situation and what is being learned" (Kolb \& Kolb, 2009, p. 6).

It is evident through published scholarship that some scholars in the field of sport management have been applying Kolb's model of experiential learning theory to their classrooms (Bower, 2013; Miller, Meaney, \& Podlug, 2012; Pauline, 2013; Turesky and Gallagher, 2011) in recent years. For example, through her semester long event management course, Pauline (2013) found that

Students developed the ability to progress from "noticing" or "making sense" to "making meaning" from their experiences" and that "once the students learned the structure of the course, course content, and got immersed with the event, the reflection process was an eye opening experience for the students to learn about themselves and the course material in a different perspective (p. 10).

Experiential learning theory will help to guide this particular study in many ways. On one hand, the theory of experiential learning can be applied to the development and adaptation of the survey instrument. In particular, faculty will be asked to answer questions related to their own experiential learning practices within the survey. They will 
also be asked to reflect on how they feel experiential learning impacts their own students' learning. Another way experiential learning theory informs this study is through the development of research questions and hypotheses. While faculty attitudes regarding student learning is one component to the study, the study also seeks to understand how individual faculty experiences impact their own application of and attitude towards experiential learning practices. In order to determine how faculty experiences, impact current application and attitudes towards experiential learning, questions like "what are the differences for faculty with prior sport industry experience?", "what are the differences for faculty based on educational background?", and "what are the differences for faculty based on prior teaching experience" will each guide the analysis and discussion.

\section{Research Questions}

The following research questions will guide the study

$\mathrm{R}_{1}$ : Which experiential learning techniques are utilized most often by sport management faculty across sport management programs?

$\mathrm{R}_{2}$ : What are the attitudes of faculty, as they relate to the application of experiential learning techniques and their impact on student learning?

$\mathrm{R}_{3}$ : In what ways do academic and professional experiences impact faculty attitudes towards the implementation of experiential learning techniques? 


\section{Definition of Terms}

The operational definition of terms used within this study included:

1. Sport management: The study and practice of all people, activities, businesses, or organizations involved in producing, facilitating, promoting, or organizing any sport-related business or product (Pitts \& Stotlar, 2002).

\section{National Association for Sport and Physical Education (NASPE): A} professional organization comprised of individuals engaged in the study of human movement and the delivery of sport and physical activity programs.

3. North American Society for Sport Management (NASSM): A professional organization comprise of individuals involved in studying the fields of sport, leisure, and recreation. The stated purpose of NASSM (2016) is to "promote, stimulate, and encourage study, research, scholarly writing, and professional development in the area of sport management".

\section{The Commission on Sport Management Accreditation (COSMA): A} specialized accrediting body whose purpose is to "promote and recognize excellence in sport management education worldwide in colleges and universities at the baccalaureate and graduate levels through specialized accreditation" (COSMA, 2016)

5. Curriculum: The planned and guided learning experiences and intended learning outcomes, formulated through the systematic reconstruction of knowledge and experiences (Tanner \& Tanner, 1980).

6. Pedagogy: The method and practice of teaching, especially as an academic subject or theoretical concept. 
7. Student learning: The student's ability to connect and apply concepts through the use of experiential learning techniques.

8. Experiential learning: "A method of learning where students gain knowledge through observation and interaction with situations or experiences, as opposed to traditional learning, where students learn through reading, lecture, and/or testing" (Itin, 1999).

9. Volunteer exploration: Occurs when students complete some kind of unstructured, service-based experience where they provide hours of their time in order to assist a local organization as well as to gain experience in some area of the sport management field.

10. Apprenticeship: A formal entry level work experience that involves observation and instruction from masters, guided practice, and finally, progression into performance of tasks that ultimately leads to independent work by the learner (Ferris \& Perrewé, 2014). An apprenticeship typically occurs prior to a practicum or internship experience.

11. Classroom-Based Experiential Learning: Occurs when students participate in experiential learning activities in the classroom. Examples include role playing, case study, team based learning (TBL), guest speakers, and client-based projects.

12. Practicum: A field experience designed to meet specific academic objectives, often in exchange for academic credit. They can be general and interdisciplinary and are sometimes related to pre-professional training (Stanton \& Ali, 1987). In sport management, practicum experiences are typically shorter than internships and often occur earlier in the sequence of study (Parkhouse, 2001). 
13. Internship: Occurs when students complete a comprehensive work experience through either a part-time or full-time internship experience in the sport management field. Often, these experiences are unpaid, however students receive credit hours at their institution of higher learning.

\section{Significance of the Study}

The results of this particular study could be significant for several groups. Sport management program directors, sport management faculty, sport management students, sport industry practitioners, as well as those professionals working to set COSMA curricular standards, could all benefit from an increased knowledge of how sport management faculty are applying experiential learning techniques across programs. While the academic field of sport management appears to have shifted towards a more applied approach to teaching and learning in recent years, a research gap remains in regards to the extent to which experiential learning practices are actually being implemented inside and outside of the classroom. The results of this particular study may help sport management program directors to identify a future model for curriculum design that involves more opportunities for experiential learning. Exploration into the results of this study would allow faculty to reflect on their own teaching practices, and consider what others are doing to incorporate experiential learning into the classroom. Current and future sport management students would become more aware of the experiential learning practices occurring within their academic field. Sport management practitioners who seek to hire graduates with more applied experience could also be impacted by the results of this study. Finally, the results may also help to identify a need 
for increased training of sport management doctoral students in the area of pedagogy and curriculum design.

The results of this study also have the potential to add to the greater, ongoing debate within the field of sport management regarding the purpose of a sport management education. Is that purpose to provide a theoretical or applied education? Is it a combination of both? A widespread analysis of experiential learning across sport management programs can help gauge how far faculty within sport management programs have moved towards an applied and experiential framework. 


\section{CHAPTER II}

\section{REVIEW OF LITERATURE}

\section{Overview}

The purpose of this dissertation is to assess the degree to which sport management faculty incorporate experiential learning techniques into their curriculum, and to determine faculty attitudes towards experiential learning practices in regards to their impact on student learning. This chapter presents the relevant literature pertinent to the research questions. This review is divided into three sections. Section one reviews the history and evolution of sport management pedagogy. Section two synthesizes experiential learning practice in higher education. Finally, section three reviews the application of experiential learning across sport management academia.

\section{The History and Evolution of Sport Management Pedagogy}

Though still a relatively young area in the context of higher education, sport management academia has evolved substantially over the last five decades. The first sport management academic program was believed to have been developed at Ohio University in 1966, thanks to a call to action from sports practitioners like Walter O'Malley of the Brooklyn Dodgers, and other sport practitioners, who campaigned for a specified academic program that would train students to manage sport (Masteralexis, Barr, \& Hums, 1998). Since its inception, popularity of the sport management major across America, and other parts of the globe, has skyrocketed. This growth can likely be 
attributed to the explosion of the commercial sport industry into a multibillion dollar industry, along with generally high student interest in the major. The number of institutions offering undergraduate sport management degrees has grown from just 20 programs in 1980 (Mahony \& Pitts, 1998) to over 300 undergraduate programs in colleges and universities in the United States today (NASSM, 2016). Outside of the United States, there are an additional 56 undergraduate programs housed in Canada, Europe, Australia, New Zealand, Africa and Asia (NASSM, 2016). As popularity for the major grew quickly, scholars realized a need for a uniform set of curriculum standards. The National Association for Sports and Physical Activity (NASPE) was formed in 1986. One of its primary goals was to develop the first set of curriculum guidelines for sport management programs in higher education. However, because the academic discipline was so new and unsupported by previous research, there were discrepancies regarding what programs should teach and thus, what their underlying mission should be.

Early sport management programs were often tied in with other kinesiologyrelated areas like exercise, physical education, and dance (Bowers, Green, \& Seifried, 2014). In fact, Brassie (1989) found that in the late 1980s, most sport management programs were housed within physical education programs and served as an alternative to physical education teacher education programs. Dr. Earle Zeigler, and other scholars in his camp, agreed with the housing of sport management programs amongst physical education schools. One of the founders of NASSM, Zeigler (1994) viewed the core mission of sport management as one that was focused on the management of sport related to physical activity and health education, not necessarily the business of sport. Alternatively, Sawyer (1993) argued that the sport management discipline could not 
remain under the umbrella of physical education, as it was expanding in ways that went far beyond the scope of physical education. He believed sport management programs would be better served within recreation management departments or even freestanding sport management departments. As popularity for the major grew and comprehensive health, physical education, and recreation departments began to form, sport management programs would move towards a more singular, independent major. Eagleman and McNary (2010) found that by 2010, 45\% of sport management programs were housed within comprehensive health and recreation schools, while $24.8 \%$ were found in schools of education, $14.5 \%$ in business schools, and nearly $3 \%$ operated independently within a school of sport management. These shifts in residency over the years have led to some sport management programs moving towards a more business-oriented approach (Jones, Brooks, \& Mak, 2008). This transition can also likely be attributed to a changing sport marketplace within the United States and other Western countries, as well as the evolution of physical education and exercise science programs respectively (Sawer, 1993).

When the National Association for Sports and Physical Activity (NASPE) developed a task force in 1986, their purpose was to take stock of sport management programs in higher education. Prior to this point, little to no work had been done to study the young, yet burgeoning area of study on college campuses. A 1987 study of sport management programs conducted by the task force found an overall lack of consistency of courses offered among the 40 undergraduate and 32 graduate programs offered at the time (Parkhouse, 1987). Other studies around the same time raised questions about the 
quality of sport management curriculum being offered (Gleason, 1986; Hardy, 1986, Lynton, 1983, \& Parkhouse, 1984).

One of the major issues early on related to the lack of applicability of many of the existing sport management programs. In their comprehensive study of sport management programs, Parkhouse (1987) found that many programs were developed without thought for appropriateness or applicability to the field of sport management. Rather, sport management programs were often developed as a modification to existing physical education programs in order to appeal to students who sought after the more marketable major (Parkhouse, 1984). In other words, simply changing the name of the program to sport management led to increased student interest. Despite the change in name, subsequent programs remained largely focused on physical education. This was primarily due to the existing faculty having backgrounds in coaching and physical activity, with little to no training in the field of sport management. Another concern for scholars at the time was the lack of sport-specific course offerings for students within sport management programs. In her comprehensive study of sport management programs, Parkhouse (1987) found that the majority of programs offered just one to three electives or required courses in foundational sport management courses, despite their claims of offering a full sport management major. Another concern for scholars in the 1980s was the lack of distinction between graduate and undergraduate sport management course offerings, with many programs housing both levels showing crossover course offerings. At the time, schools with graduate programs were encouraged to look to business administration programs as a guide for developing more challenging and sophisticated curricula (Parkhouse, 1987). Hardy (1986) also argued that graduate programs should be focused on producing sport 
managers ready to enter the workforce, rather than entry-level technicians. Many of the concerns that came out of those studies of the 1980s would be addressed in the following decade, thanks in large part to the development of the first national curricular standards for sport management programs.

In response to the previously discussed criticisms of the time, in 1993, NASPE formed a coalition with the North American Society for Sport Management (NASSM), in order to create a set of voluntary accreditation standards for sport management programs, calling them The Standards for Voluntary Accreditation of Sport Management Programs (NASPE-NASSM, 1993). The approval process would be managed by the Sport Management Program Review Council (SMPRC), an independent entity that's primary purpose would be to review sport management programs. Those particular standards created minimum competency standards for bachelor, masters, and doctoral programs within the field of sport management. The development of the standards would serve as "a guide for faculty necessitating curriculum revisions" (Eagleman \& McNary, 2010, p. 2), thus making it an easier process for programs to determine necessary curriculum changes. In addition to providing a set of standards, the process of curriculum review now provided a level of accountability that previously did not exist within the field of sport management.

For undergraduate sport management programs, three component areas were developed by the NASPE-NASSM standards, including: foundational areas of study (courses in business management, marketing, finance, etc.), sport foundation areas of study (courses in sport psychology, sport history, sport law, etc.), and finally field experiences including practica and internships (Brassie, 1989). These standards would 
spur another shift towards an even more practical, applied field in the late 1990s and that shift would continue into the 2000s. As previously discussed, Weese (1995) called for scholars to revise their theoretical orientation to one of a more practical, applied nature, in order to better serve the stakeholder group of sport practitioners, as well as its students. Relying on Dewey's theory of experiential learning, these researchers suggested that in order to reflect the changing commercial aspects of the sport industry, and evolving student body, programs needed to adapt and provide students with both service learning and internship opportunities outside of the traditional classroom experience. They also pointed out a lack of literature interested in sport management pedagogy and called for educators to critically examine their own practices.

In 2005, representatives from NASPE and NASSM formed a task force to discuss the future of sport management program review, this time with their sights set on developing a true accreditation body (COSMA, 2016). After several meetings and review processes, the Commission on Sport Management Accreditation (COSMA) was formed in 2007. The current standards for COSMA accreditation require a number of specific content areas or Common Professional Components (CPC), which can be seen in Table 1. The six core components for a program accredited under COSMA are classified as 1) social, psychological, and international foundations, 2) ethics in sport management, 3) sport marketing \& communication, 4) finance, accounting \& economics, 5) legal aspects of sport, and 6) integrative experience.

The COSMA Accreditation manual states that a successful sport management program "recognizes the role of practical and experiential learning as a relevant component of sport management curricula" and that accreditation under COSMA 
"requires that the design of each program offered by the academic unit/sport management program be consistent with current, acceptable practices and the expectations of professionals in the academic and sport management communities" (COSMA, 2016, p. 3). It is evident in this description that COSMA officials recognize the need for comprehensive input when developing curriculum, however, it is unclear to what extent COSMA officials have relied on practitioner input to develop and maintain accreditation requirements. Despite COSMA's inclusion of integrative experiences and overall interdisciplinary approach, it is important to note that just 43 sport management programs out of more than 400 are currently accredited under COSMA standards (COSMA, 2016).

\section{Experiential Learning Practices in Higher Education}

It is likely that some form of experiential learning has been taking place on college campuses in America since the early 1900s. Early examples of experiential learning on college campuses include cooperative learning and field-based learning (Lewis \& Williams, 1994). When colleges first started offering cooperative education experiences, they were often a combination or classroom study and work experience, much like today's formal internship. Science-based fields were the first to have students participate in field-based learning, a process in which students go outside and make observations of various objects and structures (Lewis \& Williams, 1994). While the concept of experiential learning has existed for centuries, the term experiential learning was first used in the 1970s as a way to describe adult learners and their lifelong work experiences (Hoffman \& Michael, 2010). The widespread use of experiential learning techniques in higher education settings began to occur in the early 1990s, not long after Kolb published his Experiential Learning Cycle (Kolb \& Kolb, 2009). 
In their assessment of undergraduate education in the mid-90s, Barr and Tagg (1995) proposed a paradigm shift in American education. Rather than provide instruction, their analysis suggested that institutions of higher education now sought to produce learning. In the traditional Instruction Paradigm, knowledge was transferred from faculty to students. In the new Learning Paradigm, faculty encouraged students to discover and construct knowledge through holistic learning environments (Barr \& Tagg, 1995). This shift towards more experiential education in institutions of higher education has continued into the early $21^{\text {st }}$ century, as millennial students have come to expect an engaging and interactive learning environment (Mangold, 2007). Additionally, scholars have found that exposure to experiential education positively impacts student learning outcomes, as well as persistence and retention rates (Eyler, 2009; Pierson \& Troppe, 2010).

In the field of sport management, Parkhouse (2001) defined two categories of experiential learning activities: discrete and non-discrete. Discrete experiential learning activities are experiences that occur separate from the on-campus educational experience, and non-discrete experiential learning activities are experiences that occur as an extension of an on-campus learning activity. She suggests that examples of discrete experiential learning activities include cooperative education, field study, practica, internships, and service learning, while examples of non-discrete experiential learning activities include field trips, interviews, site visits, and role play activities (Parkhouse, 2001). Foster and Dollar (2010) are well known for their study and support of experiential learning. They developed the Foster Five-Step Experiential Learning Process Model, which encourages sport management programs to provide experience both inside 
and outside of the classroom to students prior to applying for their first full-time position in the sport industry. The five steps of the model include: volunteer exploration, apprenticeship, classroom, elective, and culminating internship. Each step within the model will be utilized as a variable within the current study, therefore a more in depth explanation of each is provided below.

Volunteer Exploration. The concept of volunteer exploration can be summarized as a students' active involvement in which they provide hours of their time in order to assist a charitable or non-for-profit organization, as well as to gain experience in some area of the sport management field (Foster \& Dollar, 2010). In sport management, examples could include volunteering to work for an organization planning a charitable $5 \mathrm{k}$ road race or golf outing.

Volunteer exploration is similar to service learning, which has been an element of higher education learning since the late 1960s. Service learning occurs when civic responsibilities are used as a tool to connect classroom theories (You \& Rud, 2010). A primary distinction between volunteer exploration and service learning is that service learning involves a classroom component, which isn't always true of volunteer exploration.

A number of studies have supported faculty use of service learning as a positive tool that contributes to student learning and growth (Kuh, 2008; Haeg \& Lindstrom, 2008; You \& Rud, 2010). For example, Haeg and Lindstrom (2008) found that service learning opportunities helped students to develop relationships with potential mentors in faculty or community leaders. In their study of sport management students specifically, Bennett, Henson, and Drane (2003) found that students exposed to service experiences 
had improved social interaction skills, resume building, awareness of social responsibility, development of practical skills, and interaction with others from diverse cultures. Service learning can also provide the unique opportunity for students to reflect on their own personal values related to social and cultural issues (Rhoads, 1997). In addition to positive learning outcomes of students, faculty tend to support the use of service learning, as evidenced by a national survey in which $80 \%$ of faculty across academic areas said they believed students should participate in some kind of servicerelated activity (Sax \& Astin, 1997). In their study of student experiences with service learning in sport management, Bennett, Henson, and Drane (2003) suggest that servicelearning programs have been adopted by many faculty across the field of sport management. Further, a more widespread examination of service-learning across college campuses revealed that college students are participating in service-learning experiences in sport management settings at high levels (Valerius, Keller, Doyle, \& Collins, 1998).

Apprenticeship. An apprenticeship is defined as a formal entry level work experience that involves observation and instruction from masters, guided practice, and finally, progression into performance of tasks that ultimately leads to independent work by the learner (Ferris \& Perrewé, 2014). The concept of apprenticeship can likely be traced back to the Middle Ages when skilled trades were first passed down from master to apprenticeship. According to Ferris and Perrewé, an apprenticeship is inherently tied to the concept of mentoring, as the student relies heavily on the master or practitioner for both knowledge and guidance in a particular area.

In sport management, an apprenticeship is viewed as entry level work experience related the sport management field. According to Foster and Dollar (2010), an 
apprenticeship should be completed by the student in their freshman or sophomore year, after completing some sort of volunteer exploration. An apprenticeship in sport management is also viewed as an opportunity for students to learn about a particular segment of the sport industry, and thus, determine whether or not that is an area they want to pursue a future career. An example of an apprenticeship in sport management is a student working with a minor league sports team's sales department. During the apprenticeship, the student observes a sales executive as they make cold calls, respond to customer service concerns, and fulfill sales orders. The student then has the opportunity to practice these skills, while still receiving guidance and constructive feedback from the sales executive. By the end of the apprenticeship, the student will be able to independently perform the tasks and will leave the apprenticeship with a better understanding of their own career interests.

Classroom-Based Experiential Learning. Classroom-based experiential learning techniques come in various forms, and can also be described as experiential education. According to Parkhouse (2001), experiential education is a pedagogical teaching method that facilitates experiential learning by the student. Examples of classroom-based experiential techniques include: role playing, laboratory work, simulation exercises, student-led class sessions, and group learning activities (Parkhouse, 2001).

In sport management, case studies and client-based projects are also sometimes utilized to encourage experiential learning. In fact, an entire journal is dedicated to the development of case studies in sport management. The purpose of Case Studies in Sport Management is to "enhance pedagogy in the discipline through the dissemination of 
teaching cases across varied topics consistent with the COSMA Common Professional Component topical areas, including sport management, marketing, finance, and law" (p. 1). As sport management faculty implement case studies as part of a classroom project, students are given a set of facts and information related to a specific problem for a sport organization, and ultimately are tasked with solving the problem through active decisionmaking. The case study method is experiential in nature as it allows students to assume roles of sport industry practitioners, and then requires them to utilize skills such as critical thinking, strategic decision-making, creativity, teamwork, and leadership (CCSM, 2016).

Client-based projects are another example of an experiential learning technique utilized by sport management faculty. Client-based projects allow students to gain realworld experience through a classroom project that is based on the partnership with an organization outside of the University. Students are often assigned roles and given realworld goals to attain by the outside organization. Studies have shown that participation in a client-based project can help students develop real-world skills that are valued by recruiters (Bush, 2009). Examples of client-based projects in sport management are evident in Pauline and Pauline's (2008) sport sponsorship activation project as well as Pierce and Petersen's (2015) model for implementing a client-based ticket sales center as part of a sales class.

Practicum. Practicum experience is defined as a field experience designed to meet specific academic objectives, often in exchange for academic credit. They can be general and interdisciplinary and are sometimes related to pre-professional training 
(Stanton \& Ali, 1987). In sport management, practicum experiences are typically shorter than internships and often occur earlier in the sequence of study (Parkhouse, 2001).

According to Foster and Dollar (2010), this step in the experiential learning process is meant for students to gain more experience in the field with varying responsibilities from any prior apprenticeship or volunteer experience. At this point in the process, students are expected to have a better idea of what career path they want to follow, and thus, the practicum can be utilized as an opportunity to gain specific industry experience related to their career goals. For students still unsure of their career goals, the practicum can serve as additional exploratory hours to search for career interests. One major component separates most sport management practicum experiences from internship experiences. According to Schneider and Stier (2006), students often complete their practica as part of a class, where an internship is often completed as an individual experience. The classroom component allows for reflective activities and greater involvement by the instructor, as students are often still exploring their interests when completing a practicum experience.

Internships. Internships can be defined as a type of field experience that are "structured and career-relevant work experiences obtained by students prior to graduation from an academic program" (Taylor, 1998, p. 68). An internship is often considered to be a culminating experience of a student's academic progress (Bell \& Countiss, 1993; Sutton, 1989). In the sport management context, an internship can also be referred to as a field experience (Schneider \& Stier, 2006). Foster and Dollar (2010) classify this experience as a full-time internship to be experienced after all other course work has been 
completed. Students seeking an internship should have narrowed in on specific career interests, and should seek an internship related to that experience.

As opposed to the practicum experience, internships are often completed individually by the students, and rarely involve a class component (Schneider \& Stier, 2006). According to Cuneen and Sidwell (2003), there are three benefits that students obtain through the completion of an internship. Those benefits include the opportunity to practice professional skills and apply theoretical concepts to real-world issues, the opportunity to problem solve and think critically beyond classroom examples, and finally, internships often socialize students toward values and norms of a particular sport organization. Hunter and Mayo (1999) state that an internship occurs when "sport management students are literally immersed in the culture of the business of sports" (p. 76).

According to Schneider \& Stier (2006), sport management field experiences like internships require two supervisors, one on-campus (field experience coordinator) and one at the sport organization in which the internship is taking place (on-site supervisor). "In almost all cases, the field experience coordinator will be either a sport management professor or person on campus, identified as the individual responsible for placing the student interns and overseeing the students' internship experiences at the various site locations" (Schneider \& Steir, 2006, p. 38). In order to facilitate this level of supervision, the field experience coordinator must maintain a high level of communication with both the students and on-site supervisors.

It is clear that over time, institutions of higher education have continued to embrace the concept of experiential education as an effective pedagogical approach. 
Understanding both the theoretical development of experiential learning theory, and its practical application, is crucial for the development of this study. Having this foundation provides a lens through which to view the current study, in regards to developing research questions, adapting an appropriate survey tool, and analyzing results.

\section{Experiential Learning in Sport Management Academia}

Over the last 30 years, practitioners within the sport industry have often questioned sport management programs and their ability to teach practical skills to sport management students (Helyar, 2006). Historically, sport management programs have placed emphasis on theory-based courses like philosophy of sport, history of sport, sport psychology, and sport law, which remains to be the second most required course among sport management programs (Eagleman \& McNary, 2010). That theory-based approach left little time for emphasis on practical courses like sport marketing, sport sales, event management, and sport communication.

Sport industry practitioners in hiring positions have, at times, questioned the value of a sport management degree. They argue that students in sport management programs don't get enough real-world experience or practice prior to entering the field, resulting in a preference to hire someone with experience over a degree (Cuban, 2014; Dolich, 2004). In fact, a Turnkey Sports Poll of sport industry executives found that sport industry employers were more likely to hire a candidate with a business degree than a candidate with a sport management degree (King, 2009). Jeff Graubard, President of a sportmarketing firm once noted, "I have 100 resumes on my desk. Out of that, I'm interested in about two or three applicants who have actually worked in our field" (Cawley, 1999, p. 21). At a 2004 conference, Andy Dolich, former president of operations for the NBA's 
Memphis Grizzlies, revealed his disdain for sport management programs, in particular their inability to provide proper sales training: "Our business is very simple: 'Sell or die!' I am not able to find in any course catalog a curriculum for season-ticket sales, telemarketing or negotiating" (Dolich, 2004). In their study of sport management student preparedness, DeLuca and Braunstein-Minkove (2016) found that internship site supervisors noted that students lacked skills in the areas of adaptability, communication, organization, and accountability. As sport practitioners seek out employees with more and more experience each year, it becomes even more important for students to have experiential learning opportunities inside and outside of the classroom.

Dating back to 2000, sport management scholars have recognized experiential learning as an important element for sport management students seeking careers in the sport industry (Sport Management Program Review Council, 2000). However, often the experiential learning opportunities offered by sport management programs are limited to a required internship experience (Foster \& Dollar, 2010). While internship programs have been widely accepted and implemented by sport management programs (Eagleman \& McNary, 2010), scholars have noted that many students don't select an internship until their senior year, which may limit their opportunities for experiential learning. Foster, Schwarz, and Hatlem (2009), suggested that in order for students to benefit from experiential learning, they need be exposed to multiple learning opportunities throughout their time as a student. "Enhancing the educational experience with multiple learning opportunities is a proactive system exposing the student much earlier in their academic journey. Experiential learning is the term often used today to define the encapsulation of these multiple opportunities" (Foster, Schwarz, \& Hatlem, 2009, p. 422). Petersen and 
Pierce (2009) called on sport management faculty to incorporate experiential learning techniques into curriculum, noting that it provides students with an invaluable opportunity to link curriculum with sport industry practice. In their recent evaluation of sport management student preparedness, DeLuca and Braunstein-Minkove (2016) suggest programs incorporate more experiential opportunities, specifically mandatory pre-internship experience coursework where students gain formal contact hours with oncampus groups like athletics, or volunteer hours with local organizations. It is evident through the literature that a call to action of sorts has been sounded in regards to providing sport management students with multiple experiential learning opportunities.

It is important to note that a handful of scholars within the field of sport management have developed experiential learning models over the last decade (Foster \& Dollar, 2010; Irwin, Sutton, \& McCarty, 2007; Pauline, 2013; Southall, Nagel, LeGrande, and Han, 2003). Pauline (2013) developed the Sport Management Experiential Learning Process (SMELP), a model intended for use in a semester long sport management event course. Using Kolb's experiential learning theory model as a guide, she developed a process that involved the development of student knowledge through in-class discussion, student engagement with the event itself, various opportunities for student reflection, and opportunities for students to articulate learning. She found that after implementing the model throughout a semester-long event management course, students had increased engagement, professional growth, personal development, and content knowledge. Particularly, students benefited from the practice of reflection, which they said provided them with a new avenue for critical thinking and learning (Pauline, 2013). She found that 
"students developed the ability to progress from "noticing" or "making sense" to "making meaning" from their experiences" and that

Once the students learned the structure of the course, course content, and got immersed with the event, the reflection process was an eye opening experience for the students to learn about themselves and the course material in a different perspective (p. 10).

Southall, Nagel, LeGrande, and Han (2003), developed a "metadiscrete" practicum model in which faculty serve as mentors, advisors, and managers for studentemployees in their specific areas of expertise, and students act as employees serving specific clients, thus combining classroom theory with practical experience. Irwin, Southall, \& Sutton (2007) later applied the "metadiscrete" practicum model when they developed the Pentagon of Sports Training (PSST) model, which applies a client-based, experiential learning model when implementing sport sales courses. The PSST model includes five modules: philosophy, product knowledge, prospect knowledge, practice, and performance, in which students work with faculty and practitioner mentors to actually develop specific competencies in sales techniques.

Other scholars within sport management have applied experiential learning models to in-class assignments and projects with success. In their application of a clientbased experiential model within a semester long sport marketing class, Pauline \& Pauline (2008), found that students were not only able to understand the concepts by the end of the course, but were able to directly apply their knowledge successfully. McKeylvey \& Southall (2008) found that students benefited from the applied nature of their semester long sport marketing course in which students were assigned the task of selling 
sponsorship packages for a local baseball team. Finally, in their semester-long clientbased sport-sales course, Pierce, Petersen, \& Meadows (2011), found that the experimental group of students (those participating in experiential sales training), "significantly improved its ability compared to the control group to open the sales call and demonstrate enthusiasm during the sales call" (p. 81-82).

The majority of publications related to sport management pedagogy have looked at student outcomes or attitudes, while only a handful have looked at faculty attitudes towards a particular pedagogical approach (Lebel, Danylchuk, \& Miller, 2015; Wilson, 2008). As this present study seeks to analyze the application of experiential learning techniques, as well as faculty attitudes towards experiential learning as a pedagogical approach, it is important to review those studies that have previously attempted to measure pedagogical techniques using similar constructs in the field of sport management.

In his study of technology utilization across sport management programs, Wilson (2008) sought out to examine the current state of technology utilization by seeking sport management faculty input. He notes in his study that previous research had failed to examine which technologies were being taught or encouraged by sport management faculty, as well as to measure the level of sport management students' proficiency using technology. A primary goal of his research was to identify which technologies students should develop skills and attain competency in prior to entering the field. His research questions include: 
- What types of technologies were taught to sport management students in sport management courses within academic programs appearing on the NASSM list of undergraduate or graduate programs?

- What was the current technological proficiency of sport management programs appearing on the NASSM list of undergraduate or graduate programs (as perceived by sport management faculty members)?

- According to sport management faculty members what technologies were important for sport management students to learn prior to entering the workforce?

- What factors affected technology utilization of sport management faculty within academic programs appearing on the NASSM list of undergraduate and graduate programs? (Wilson, 2008, p.11-12).

In order to address his research questions, Wilson utilized a survey method of research. In this particular study, the target population included all faculty members teaching at least one sport management course at a four-year college or university listed on the NASSM website. The survey instrument itself was modeled after a survey previously used to measure technology use in an educational environment. Wilson titled his adapted survey, the Sport Management and Technology (SMaT) Survey, which was divided into four sections, included 45 items, and utilized a seven-point Likert scale to measure faculty responses. In order to insure survey validity, a panel of experts and a field test were utilized. The panel of experts was made up of 6 individuals from the sport management field and 2 individuals from the field of instructional technology. 
In his analysis of the primary survey data, Wilson utilized descriptive statistics of means, standard deviations, and correlations and independent sample t-tests were conducted in order to determine whether or not the mean scores were statistically significant. Results of the study indicated that e-mail was the technology most often taught or encouraged and that blogging was the least. E-mail was also considered by faculty as the most important communication technology for students to learn prior to entering the field, along with research technology, while blogging was considered the least important. Overall, the study suggested that sport management faculty members do not teach or encourage technology utilization in their classrooms to a great extent (Wilson, 2008).

Wilson's study informs the present study in a few ways. Both the purpose of his study, and subsequent research questions provide a foundation for which to base the present study. Wilson sought out to determine the ways in which faculty implement technology, much in the same way that this study will seek to determine the ways in which faculty utilize experiential learning techniques. Wilson's choice to adapt a prior study, and his process for confirming validity and reliability also helps inform the present study, as a survey instrument has been adapted and will need to be tested prior to actual data collection.

Another study that helps inform the current study is Lebel, Danylchuk, and Millar's (2015) study that measured faculty perceptions of social media as a learning tool across sport management programs. Much like the present study, their study focused on a specific pedagogical approach (social media), and then sought out to investigate both the use of social media across sport management programs, and more specifically, how sport 
management faculty use social media as a teaching and learning tool (Lebel, Danylchuk, \& Millar, 2015). The following research questions guided their study:

- What are the social media and general technology literacies of sport management faculty?

- How are sport management faculty currently using social media as a teaching and learning tool?

- What are sport management faculty perceptions of social media pedagogies? (Lebel, Danylchuk, \& Millar, 2015, p. 42).

In order to address those questions, the researchers developed a survey instrument that was sent to sport management faculty members across both the United States and Canada. Their survey instrument was broken down into three sections: demographics, social media/technology literacies, and interpretation of social media as a teaching and learning tool.

Data analysis for the social media study included the use of descriptive statistics (frequencies and percentages) as well as means and standard deviations. Descriptive statistics were primarily used to examine trends related to social media implementation, as well as faculty proficiency and usage rates. The researchers also utilized one-way ANOVA with Bonferroni post hoc and t tests in order to examine group differences across sport management faculty (Lebel, Danylchuk, \& Millar, 2015). The results of this particular study indicated that just $61 \%$ of study participants had previously incorporated social media into their course design; however, a majority of faculty agreed that social media could provide positive enhancement to teaching and learning (Lebel, Danylchuk, \& Millar, 2015). 
Label, Danylchuk, and Millar's study informs the present study in a few ways. The breakdown of the survey instrument helped guide the adapted survey for the present study which is also broken down into three similar sections: demographics, experiential learning technique utilization, and the interpretation of experiential learning as a teaching and learning tool. Although another survey instrument was the basis for the newly created instrument, this instrument provided a framework for how the survey should be developed. Similarly, the present study will utilize descriptive statistics in order to measure the utilization of various experiential learning techniques, but will also require more advanced statistical testing like ANOVAs and t-tests in order to determine group differences based on faculty background information.

As a growing number of scholars continue to develop and practice experiential learning models within sport management classrooms, it is evident that the inclusion of an experiential learning model within sport management courses can contribute positively to a comprehensive learning experience for students. This study seeks to discover the extent to which sport management faculty are providing experiential learning experience for students. In addition, this study will seek to understand faculty attitudes towards the implementation of experiential learning techniques and how they impact student learning. 


\section{CHAPTER III}

\section{METHODOLOGY}

This chapter describes the research design and experiential methods utilized to conduct this study, the study participants and methods of recruitment, and the method of instrumentation. Finally, this chapter addresses the data collection process. To begin, the purpose of the study will be restated. The purpose of this study is three-fold. Specifically, this study investigates the application of experiential learning practices across sport management programs. Additionally, this study seeks to examine faculty attitudes as they relate to the application of experiential learning practices and their impact on student learning. Finally, this study seeks to determine the impact of academic and professional experiences on faculty attitudes towards the implementation of experiential learning techniques. The following research questions and hypotheses will guide the study.

\section{Research Questions}

$\mathrm{R}_{1}$ : Which experiential learning techniques are utilized most often by sport management faculty across sport management programs?

$\mathrm{R}_{2}$ : What are the attitudes of faculty, as they relate to the application of experiential learning techniques and their impact on student learning?

$\mathrm{R}_{3}$ : In what ways do academic and professional experiences impact faculty attitudes towards the implementation of experiential learning techniques? 


\section{Hypotheses}

Based on previous literature in the areas of experiential learning and sport management pedagogy outlined in Chapter II, the following research hypotheses were proposed:

$\mathrm{H}_{1 \mathrm{a}}$ : The internship will be the most widely reported experiential learning technique across sport management programs, while volunteer exploration and classroom-based techniques will also be widely reported by faculty (Eagleman \& McNary, 2010; Sax \& Astin, 1997; Bennett, Henson, \& Drane, 2003).

$\mathrm{H}_{2 \mathrm{a}}$ : Faculty will generally respond positively towards experiential learning techniques and their ability to aide student learning (Wilson, 2008; Label, Danylchuk, \& Millar, 2015).

$\mathrm{H}_{3 \mathrm{a}}$ : There will be differences among faculty responses based on prior educational experience (Geurin-Eagleman \& McNary, 2014).

$\mathrm{H}_{3 b}$ : There will be differences among faculty responses based on prior work experience in the sport industry (Pierson \& Troppe, 2010).

$\mathrm{H}_{3 c}$ : There will be differences among faculty responses based on prior teaching experience (Eyler, 2009).

\section{Research Design}

This study utilized a quantitative survey design. Within the field of sport management, quantitative research utilizes statistical techniques in an effort to explain a particular phenomenon, and results are typically presented in the form of statistics (Andrew, Pedersen, \& McEvoy, 2011). Survey research is often utilized as a method for 
collecting quantitative data. With survey research, the researcher "attempts to obtain data from members of a population (or a sample) to determine the current status of that population with respect to one or more variables" (Fraenkel \& Wallen, 2003, p. G-8). The rationale for this approach is that the collection of quantitative data will allow for a largescale study that will collect information from across the sport management field. One purpose of this study is to determine the wide-spread application of experiential learning techniques across the sport management field, therefore a large sample size is required.

In his study of athletic trainer program directors and their integration of evidencebased practices within curricula, Stanek (2010) utilized quantitative survey research to collect data from a list of athletic training program directors. Through quantitative survey methodology, he produced a survey that was sent to athletic training program directors in order to determine the extent to which programs were utilizing evidence-based practices within their curriculum. Data analysis revealed that athletic training education programs appear to be providing students with an adequate entry-level experience into EBP, but that only $22 \%$ of program directors indicated their program contained a course specifically designed to teach the skills of EBP (Stanek, 2010). The present study will take a similar approach in producing a survey for quantitative data collection. As previously discussed in Chapter II, a number of other studies helped frame the present study in regards to methodology and instrumentation.

\section{Data Collection Procedures}

All sport management faculty currently subscribed to the NASSM listserv were contacted for participation in the study. As of December 2015, there were 815 subscribers to the NASSM ListServ. It is important to note that not all subscribers to the NASSM 
listserv are sport management faculty. Sport industry practitioners, as well as prior attendees to NASSM conferences also subscribe to the listserv. In the e-mail communication, all faculty were invited to participate, including adjunct faculty and doctoral students with teaching experience. In order to increase the likelihood of participation, faculty were notified that their participation would enter them into a drawing for one of two (2) \$50 Visa gift cards. In sport management research, some examples of incentives or inducements, are direct monetary rewards, free merchandise, and participation in drawings (Andrew, Pedersen, \& McEvoy, 2011). Faculty were first contacted via electronic mail on December 11, 2015, requesting their assistance and participation of the study. The survey was delivered through a web link via SurveyMonkey.com. From the initial outreach, 108 usable surveys were returned. A second e-mail communication was delivered on January 13, 2016, about a month later. This e-mail served as a reminder of the study and the active survey link. Another 28 usable surveys were returned at this point in time.

\section{Instrumentation}

A survey instrument was adapted from a previously tested questionnaire that was utilized to measure service learning across marketing departments in higher education (McIntyre, Webb, \& Hite, 2005). Permission was received from one of the authors for use of the original survey (F. McIntyre, personal communication, September 11, 2015). The purpose of that study was to determine the ways in which service learning was being implemented by faculty, as well as to determine group differences among faculty based on demographic information. In order to adapt section 1 of the original survey to incorporate experiential learning constructs, Foster and Dollar's (2010) five categories of experiential 
learning in sport management were utilized in place of the original service learning-related activities (Table 1). As previously used in the original survey instrument, Andreasen's (1995) stages of behavior change were kept as a construct to measure faculty implementation of the various experiential learning techniques (Table 2). In addition, section 2 of the original survey, which measured faculty opinions about the value of service learning was kept, with the term "service learning" simply replaced by the term "experiential learning". Section 3 of the original survey, which focused on faculty involvement with non-profit organizations was removed, as that information is not relevant to the present study. Section 4 of the original survey measured faculty agreement/disagreement about service learning and its impact on student learning. The adapted survey utilized 8 of the original constructs, and again replaced the term "service learning" with the term "experiential learning". The newly adapted survey has been titled the Experiential Learning in Sport Management (ELSM) Survey. A 7-point Likert scale was utilized to measure faculty agreement and disagreement in regards to each item. Table 3 below lists a sample of the items from the original survey and the modifications made for use in the ELSM survey instrument.

Table 1

Foster and Dollar's (2010) Five-Step Experiential Learning Process Model

\begin{tabular}{l}
\hline Technique \\
\hline Volunteer exploration \\
Apprenticeship \\
Classroom \\
Practicum Elective \\
Culminating Internship \\
\hline
\end{tabular}


Table 2

Andreasen's (1995) Stages of Behavior Change

Stage

I have never used this method

I am considering this for the near future

I have used this once or twice

I use this on a regular, ongoing basis

I have used this in the past but do not plan to use it in the future

Table 3

Comparison of Survey Items for ELSM Survey (Section 3)

\begin{tabular}{lll}
\hline Item \# & Original Item & Modified Item \\
\hline 1 & $\begin{array}{l}\text { Service learning teaches } \\
\text { students interpersonal skills. }\end{array}$ & $\begin{array}{l}\text { Experiential learning teaches } \\
\text { students interpersonal skills. }\end{array}$ \\
2 & $\begin{array}{l}\text { Service learning leads } \\
\text { students to see links between } \\
\text { theory and practice. }\end{array}$ & $\begin{array}{l}\text { Experiential learning leads students } \\
\text { to see links between theory and } \\
\text { practice. }\end{array}$ \\
& $\begin{array}{l}\text { Service learning teaches } \\
\text { students problem-solving } \\
\text { techniques. }\end{array}$ & $\begin{array}{l}\text { Experiential } \\
\text { students } \\
\text { techniques. }\end{array}$ \\
\hline
\end{tabular}

The goal of the Experiential Learning in Sport Management (ELSM) survey instrument was threefold. First, the goal of the survey instrument was to determine basic demographic information related to faculty background, including gender, age, education, and other information specific to their prior work experience. This information was gathered through a series of multiple choice and fill-in-the-blank questions. The second goal of the survey instrument was to determine faculty utilization of experiential learning 
techniques inside and outside of the classroom. This information was gathered through a series of Likert-Scale questions regarding specific experiential learning techniques and the faculty member's own application, using Andreasen's (1995) stages of behavior change. A final goal of the instrument was to examine faculty attitudes as they relate to the application of experiential learning techniques and their perceived impact on student learning. This information was gathered through a series of Likert-Scale questions regarding the faculty member's own attitudes towards experiential learning. In addition, an open-ended question regarding faculty use of experiential learning concluded this section of the survey.

\section{Study Variables}

This study included both dependent and independent variables. Independent variables are variables believed to be a precursor to dependent variables, while dependent variables are measurable variables, or outcomes that are observed (Ary, Jacobs, Razavieh, \& Sorensen, 2006). The independent variables in this study are each related to prior life experience or background of faculty members. The dependent variables are specifically related to the constructs being measured in the survey. See the table below for more information regarding the variables in this study: 
Table 4

Experiential Learning in Sport Management (ELSM) Study Variables

\begin{tabular}{ll|l}
\hline Independent Variable(s) & Dependent Variable(s) \\
\hline Prior Teaching Experience & $\begin{array}{l}\text { Faculty } \\
\text { implementation of } \\
\text { experiential learning } \\
\text { techniques }\end{array}$ & $\begin{array}{l}\text { Faculty attitudes } \\
\text { towards experiential } \\
\text { learning and its impact } \\
\text { on student learning }\end{array}$ \\
Terminal Degree Program/School & & \\
\hline
\end{tabular}

\section{Validity and Reliability}

With any quantitative study, certain variables have the potential to threaten validity and reliability. The following errors related to sampling and data collection procedures can threaten external validity of this study: sampling error and non-response error. Sampling error occurs when individuals who are not representative of the target population are included in the sample (Andrew, Pedersen, \& McEvoy, 2011). Prior to taking the survey, potential respondents were informed of the target pool and non-faculty were dissuaded from participating in the study. In order to further avoid sampling error, any survey respondent who did not select a faculty classification in question 8 of the survey was removed from the data analysis. In addition, Non-response error involves the subjects' failure to respond or the researcher's inability to locate subjects (Miller, 2001). In order to avoid non-response error, the present study attempted to survey an entire population of sport management faculty who currently subscribe to the NASSM List Serv. With a potential sample of over 800 individuals, the risk of non-response error was lower and there is greater ability to generalize to a larger population. 
Internal validity refers to the instrument's ability to accurately measure what it is intended to measure (Andrew, Pedersen, \& McEvoy, 2011). In other words, did the instrument address the research questions posed by the study? In order to insure internal validity of this survey instrument, operational definitions were supplied for each experiential learning technique, as well as more general definitions of experiential learning and student learning. In order to insure face validity of the newly adapted instrument, two external sport management faculty were asked to review its contents and provided feedback. Despite these measures, there may have been some confusion related to survey item \#1, which asked faculty to indicate their level of involvement as an instructor for each of Foster and Dollar's (2010) experiential learning techniques. A few respondents mentioned in the follow-up comments that they may not have personalized utilized a technique, but that didn't mean that their department didn't.

Reliability is also a concern in developing a quantitative survey study. Reliability refers to the extent to which a survey instrument will produce the same results in repeated tests (Andrew, Pedersen, \& McEvoy, 2011). As the scales utilized in the present study have been previously utilized in a study, the reliability has already been proven (Andreasen, 1995; Foster \& Dollar, 2010; McIntyre, Webb \& Hite, 2005).

\section{Data Analysis}

While quantitative and qualitative research have been identified as the two broad types of research, Fraenkel and Wallen (2003) described three more specific research categories as descriptive, associational, and intervention. Because this particular area of sport management pedagogy has yet to be studied comprehensively, both descriptive and associational analysis were needed. Descriptive analysis is often utilized with the purpose 
of providing a summary of the data through measures like the mean, median, or standard deviation (Andrew, Pedersen, \& McEvoy, 2011). Associational analysis goes a step further than basic descriptive analysis in order to discover how things are related or causal (Fraenkel and Wallen, 2003). Once an initial analysis of the topic has been conducted, future qualitative studies seeking a more in-depth description of the area may be required.

In order to respond to research questions 1 and 2, the quantitative data collected was first analyzed using descriptive statistics. Using descriptive statistics, including frequencies, percentages, means, and standard deviations, each section of this study was analyzed to determine the following information. The extent to which sport management faculty are applying experiential learning techniques was identified by producing frequencies, or a list of pedagogical experiential learning techniques and how often they are utilized by faculty. Basic descriptive statistics were also used to gather information regarding faculty demographic information. Descriptive statistics were utilized to express the attitudes of faculty as they relate to the application of experiential learning techniques. In order to respond to research question 3, the survey data was analyzed using more advanced statistical analysis. Analysis of Variance (ANOVA) and Independent Samples t-testing were conducted in order to measure variability among the independent variables. This allowed the researcher to determine whether or not the lived experiences of faculty had an impact on their implementation of and attitudes toward experiential learning. Specifically, the three variables were prior teaching experience, prior industry experience, and terminal degree program of study. Prior teaching experience was broken down into two categories: "Experienced Faculty" and "Early Career Faculty". Prior 
industry experience was broken down into three categories: "No Work Experience", "Some Work Experience", and "Several Years Work Experience”. Finally, the terminal degree program of study variable was broken down by program type (business, education, kinesiology, etc.) and the number of categories varied depending on the survey responses. Post Hoc testing (Bonferroni) was conducted in cases with significant results, in order to determine which groups were different.

This chapter gave a detailed description of the methodology used for this study. The newly adapted survey instrument, titled the Experiential Learning in Sport Management (ELSM) Survey, can be found in Appendix C. 


\section{CHAPTER IV}

\section{RESULTS}

The purpose of this study was to investigate the application of experiential learning practices across sport management programs. Additionally, this study sought to examine faculty attitudes as they relate to the application of experiential learning practices and their impact on student learning. Finally, this study sought to determine the impact of academic and professional experiences on faculty attitudes towards the implementation of experiential learning techniques. This chapter focuses on the analysis of the data gathered.

\section{Analysis of Data}

In order to address the research questions above, a 15-item questionnaire was developed and sent to sport management faculty for response. The instrument was named Experiential Learning in Sport Management (ELSM) survey instrument. The ELSM survey instrument was developed through modifying a survey instrument previously developed and validated by McIntyre, Webb, \& Hite (2005), which was utilized to measure service learning across marketing departments in higher education. Permission was received from one of the authors for use of the original survey (F. McIntyre, personal communication, September 11, 2015). The ELSM survey instrument contained three sections. The first section measured faculty usage of experiential learning techniques through a series of Likert-Scale questions using Andreasen's (1995) stages of behavior 
change. The second section of the instrument measured faculty attitudes as they relate to the application of experiential learning techniques and their perceived impact on student learning. This information was gathered through a series of Likert-Scale questions regarding the faculty member's own attitudes towards experiential learning. This section also included a ranking question which asked faculty to rank what they believed to be the most effective experiential learning technique in aiding student learning. Finally, the third section of the instrument measured demographic information related to faculty background, including gender, age, education, and other information specific to their prior work experience. This information was gathered through a series of multiple choice and fill-in-the-blank questions.

Following completion of data collection, the data was coded and analyzed using the Statistical Package for the Social Sciences software (SPSS, Inc., version 22). Incomplete survey responses were removed prior to analysis. The findings of the study are presented in the following order: a) demographic information of study participants, b) faculty usage of experiential learning techniques (RQ1), c) faculty attitudes towards experiential learning (RQ2), and d) analysis of faculty academic and professional experiences impact on experiential learning application (RQ3).

\section{Demographic Profile}

The ELSM survey instrument was distributed via e-mail to subscribers of the NASSM List Serv. A total of 136 electronic surveys were completed by faculty and considered usable for analysis, resulting in a $16.6 \%$ response rate. Demographic frequency information for the respondents is provided in Table 5. The majority of respondents were male $(61.8 \%, n=84)$, compared with $38.2 \%(n=52)$ of the participants 
being female. Of the respondents, $83.8 \%$ had either a Ph.D. $(70.6 \%, n=96)$ or an Ed. D $(13.2 \%, \mathrm{n}=18)$. When reporting the school or program from which they received their terminal degree, $49.1 \%(\mathrm{n}=56)$ reported either a kinesiology and/or health sciences program, $42.9 \%(n=49)$ reported an education program, and the remaining $7.8 \%$ (9) reported a business and/or law school.

When asked to describe their current role in their department, the majority of respondents $(55.1 \%, \mathrm{n}=75)$ identified as faculty, while $22.8 \%(\mathrm{n}=31)$ identified as program director, $10.3 \%(n=14)$ identified as department chair, $10.3 \%(n=14)$ identified as doctoral students, while only $1.5 \%(\mathrm{n}=2)$ identified as adjunct faculty. In regards to teaching experience, more than half of the respondents $(61 \%, \mathrm{n}=83)$, reported 6 or more years of teaching experience, while the remaining $39 \%(n=53)$ reported 5 years or fewer. For analysis purposes, the grouping variables will be referred to as "Experienced Faculty" and "Early Career Faculty". In regards to teaching load per semester, 54.4\% $(n=74)$ reported teaching 1 to 2 courses, while $45.5 \%(n=62)$ reported teaching 3 or more courses per semester. For analysis purposes, the grouping variables will be referred to as "Light Teaching Load" and "Heavy Teaching Load".

Finally, in regards to years spent working as a practitioner in the sport industry, $18.4 \%(n=25)$ said they had no experience working the industry, while $33.9 \%(n=46)$ reported working 1-4 years, and $47.7 \%(n=65)$ reported over 5 years of experience working in the sport industry. For analysis purposes, the grouping variables will be referred to as "No Work Experience", "Some Work Experience", and "Several Years Work Experience". 
Table 5

Respondent Characteristics

\begin{tabular}{lcclrr}
\hline Gender & \multicolumn{1}{c}{$\%$} & Years Teaching & $n$ & $\%$ \\
\hline Male & 84 & 61.8 & $1-2$ & 14 & 10.3 \\
Female & 52 & 38.2 & $3-5$ & 39 & 28.7 \\
& & & $6-8$ & 29 & 21.3 \\
& & & $9+$ & 54 & 39.7 \\
\hline & & & & & \\
Level of Education & $n$ & $\%$ & Current Role & $n$ & $\%$ \\
\hline Masters & 19 & 14 & Faculty & 75 & 55.1 \\
Ph. D. & 96 & 70.6 & Department Chair & 14 & 10.3 \\
Ed. D & 18 & 13.2 & Program Director & 31 & 22.8 \\
J.D. & 3 & 2.2 & Adjunct & 2 & 1.5 \\
& & & Doctoral Student & 14 & 10.3 \\
\hline & & & & & \\
Terminal Degree & $n$ & $\%$ & Years as Practitioner & $n$ & $\%$ \\
\hline Education & 49 & 43 & None & 25 & 18.4 \\
Kinesiology & 43 & 37.7 & $1-2$ & 19 & 14 \\
Business & 9 & 7.9 & $3-4$ & 27 & 19.9 \\
Sport Management & 13 & 11.4 & $5-6$ & 24 & 17.6 \\
& & & $7-9$ & 12 & 8.8 \\
& & & $10+$ & 29 & 21.3 \\
\hline
\end{tabular}

Course Load per Semester

$\begin{array}{lll}\begin{array}{l}\text { \# of courses) } \\ \text { 1 }\end{array} & n & \% \\ 2 & 16 & 11.8 \\ 3 & 58 & 42.6 \\ 4 & 25 & 18.4 \\ 5 & 21 & 15.4 \\ 6 & 11 & 8.1 \\ & 5 & 3.7\end{array}$




\section{Findings and Results}

\section{RQ 1: Faculty Usage of Experiential Learning Techniques}

The first research question asked, "Which experiential learning techniques are utilized most often by sport management faculty across sport management programs?" Based on prior research that indicated a heavy emphasis on the internship experience, the following hypothesis was developed: The internship will be the most widely reported experiential learning technique across sport management programs, while other experiential learning projects are less likely to be reported by faculty.

Data analysis for this question required descriptive statistics that were exhibited for each experiential learning technique. The five experiential learning techniques identified in the survey instrument were based on Foster \& Dollar's (2010) Five Categories of Experiential Learning, which are identified as volunteer exploration, apprenticeship, classroom, practicum elective, and culminating internship. Using Andreasen's (1995) stages of behavior change, respondents were asked to indicate their level of involvement as an instructor for each experiential learning technique. The scale options were 1) I have never used this method, 2) I am considering using this method for the near future, 3) I have used this once or twice, 4) I use this on a regular, ongoing basis, and 5) I have used this in the past but do not plan to use it in the future. When assessing the data across Andreasen's (1995) stages of behavior change, cell sizes for faculty having used a technique with no intentions of future use were small. Since no differences exist between this group and those never using that particular technique, both were collapsed into one category that is now identified as "Non-Users". In addition, three other categories were defined in order to describe the respondents: "Contemplators", those who 
are considering using in the future, "Triers", those who have used once or twice in the past, and "Adopters", those who use on a regular, ongoing basis. The complete breakdown of respondent application of experiential learning techniques can be seen in Table 6.

In regards to volunteer exploration, $46.3 \%(n=63)$ respondents reported that they regularly use this experiential learning technique, $17 \%(n=24)$ reported that they have used it once or twice, and $20.5 \%(n=28)$ reported as non-users. In regards to apprenticeship, $34.6 \%(n=47)$ reported that they regularly use it, while nearly half of the respondents $(47.8 \%, \mathrm{n}=65)$ reported as non-users. In regards to classroom, a resounding $83.1 \%(n=113)$ reported that they regularly use classroom-based experiential learning, while just $5.9 \%$ (8) reported as non-users. In regards to practicum elective, $48.5 \%(\mathrm{n}=66)$ reported that they regularly use it, while $27.2 \%(n=37)$ reported as non-users. Finally, in regards to internship, $70.6 \%(n=96)$ reported that they regularly use it, while $21.3 \%$ $(n=29)$ reported that they have either never use it or have no plans to use it in the future.

Based on the results above, it appears that the experiential learning techniques faculty are using most often are classroom and internship. Classroom-based experiential learning is widely accepted and applied by the majority of faculty, with $83.1 \%$ saying they regularly use it, and just 5.9\% reporting as non-users. Nearly half of respondents (47.8\%) reported as non-users of apprenticeship, and just $24.6 \%$ reported as adopters, suggesting that of the five experiential learning techniques identified by Foster and Dollar (2010), it is the least likely to be adopted by faculty. While a large percentage (70.6\%) of respondents say they use internship regularly, over $20 \%$ reported that they have either never used it or have no plans to use it in the future. This disconnect is likely explained 


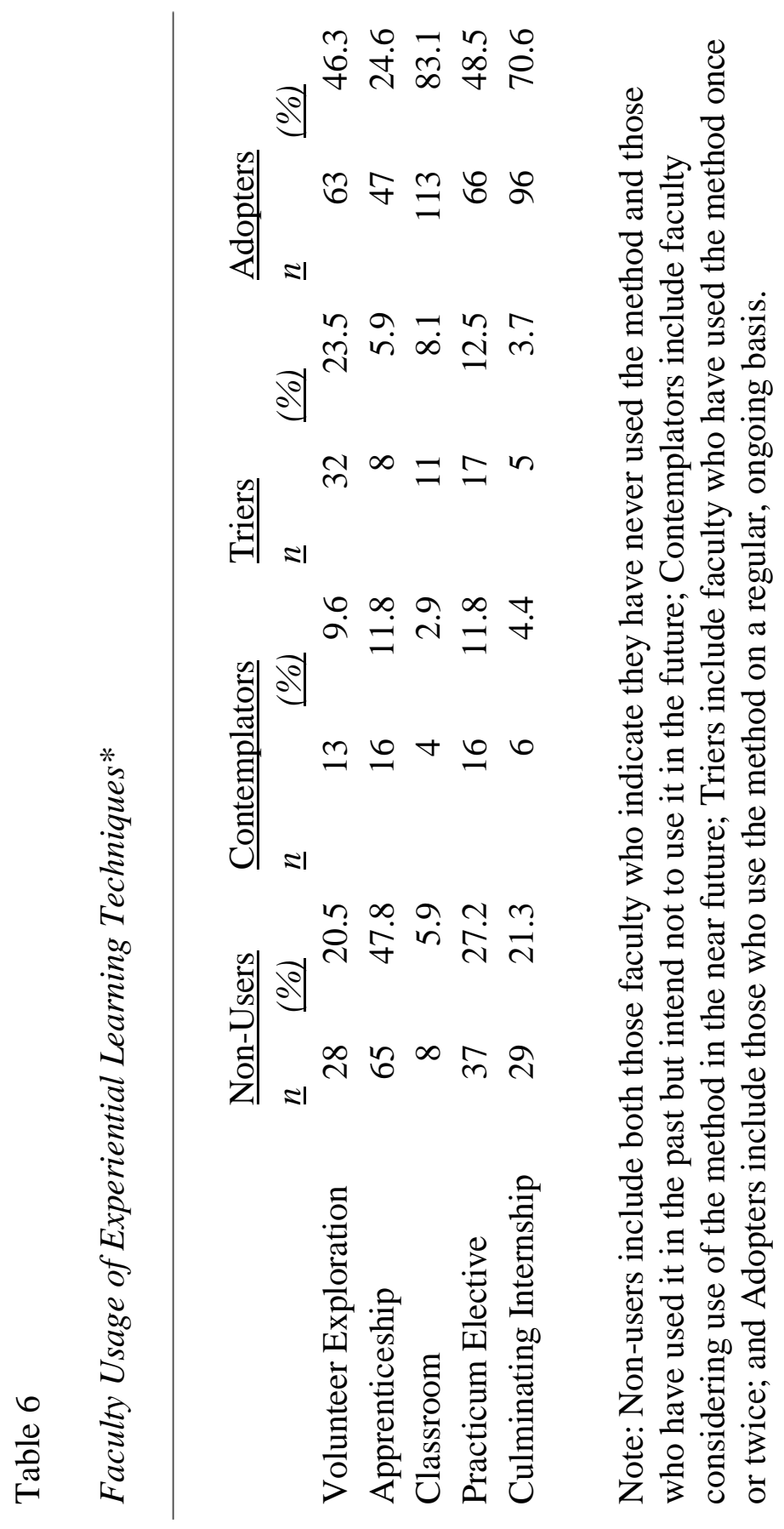


by the fact that a number of sport management programs have specified "internship coordinators", who may oversee the internship program regularly, and thus other faculty haven't had the opportunity to personally utilize internship as an experiential learning technique. The results from this research question allows for the rejection of hypothesis one, which stated that the internship would be the most widely reported experiential learning technique across sport management faculty. While $70 \%$ of respondents were "Adopters" of the internship as an experiential learning technique, classroom-based experiential learning was the most widely reported experiential learning technique from a usage perspective. Based on comments made by survey respondents in relation to this question, the most likely explanation for this disconnect relates to the formalized structure of sport management programs and how they oversee internships; with many programs designating one or two faculty with the duties, therefore leaving many faculty with no access to internship supervision.

\section{RQ 2: Faculty Attitudes Towards Experiential Learning}

The second research question asked, "What are the attitudes of faculty, as they relate to the application of experiential learning techniques and their impact on student learning?" Based on an increase in the amount of scholarly work geared towards experiential learning in the field over the last decade, the following hypothesis was developed: Faculty will generally respond positively towards experiential learning techniques and their ability to aide student learning.

In order to measure faculty attitudes towards the specific experiential learning techniques identified by Foster and Dollar (2010), faculty were asked to choose the 
experiential learning technique that they believe is "most effective" in aiding student learning. Prior to answering this question, respondents were provided with a definition for both experiential learning and student learning in the context of this study. Experiential learning was defined as "a method of learning where students gain knowledge through observation and interaction with situations or experiences, as opposed to traditional learning, where students learn through reading, lecture, and/or testing" (Itin, 1999). Student learning was defined as "a student's ability to connect and apply concepts through the use of experiential learning methods."

Of the five techniques, internship was ranked by a majority of respondents as most effective, with $58.1 \%(\mathrm{n}=79)$ choosing it. Classroom-based experiential learning came in second, with $18.4 \%(\mathrm{n}=25)$ of respondents ranking it as most effective. Volunteer exploration was only ranked by $1.5 \%$ of respondents as the "most effective" experiential learning technique. The complete breakdown of results can be found in Table 7 . Interestingly, even though internship was ranked as "most effective" by a majority of respondents, from a usage standpoint, respondents were more likely to implement classroom-based techniques. Again, the reasoning for this disconnect is likely explained by the fact that many sport management faculty members do not have the opportunity to personally oversee internship experiences, whereas all of them have them opportunity to implement classroom-based techniques if they chose. It is also worth noting that $7.3 \%$ of respondents selected "Other" when responding to this question. The majority of those respondents $(62.5 \%)$ clarified their response in the open-ended space by stating that they believed more than one of the techniques was effective and therefore could not select just one. 
Despite the findings from question one which suggest classroom-based techniques are most widely accepted from a usage standpoint, it is evident that respondents value internships and that they are viewed as the most effective experiential learning technique in aiding student learning. Again, this disconnect likely relates to the formalized structure of sport management programs and how they oversee internships; with many programs designating one or two faculty with the duties, therefore leaving many faculty with no access to internship supervision. Based on respondent comments regarding this question, it is clear that even faculty members who don't have direct contact with the internship program at their University likely still place high value on the internship experience.

Table 7

Most Effective Experiential Learning Technique

\begin{tabular}{lrr}
\hline Technique & $n$ & $(\%)$ \\
\hline Culminating Internship & 79 & 58.1 \\
Classroom & 25 & 18.5 \\
Apprenticeship & 10 & 7.3 \\
Practicum Elective & 10 & 7.3 \\
Other & 10 & 7.3 \\
Volunteer Exploration & 2 & 1.5 \\
\hline
\end{tabular}

In addition to ranking the experiential method they found most effective in aiding student learning, respondents were also asked about their attitudes towards experiential learning through a series of Likert-Scale questions. The items listed included statements regarding both student learning outcomes and faculty facilitation of experiential learning methods. Item analysis for the eight statements are provided in Table 8 . Specifically, items $3,4,5$, and 6 were used to determine respondent attitudes of experiential learning related to student learning outcomes, including such measures as interpersonal skills, 


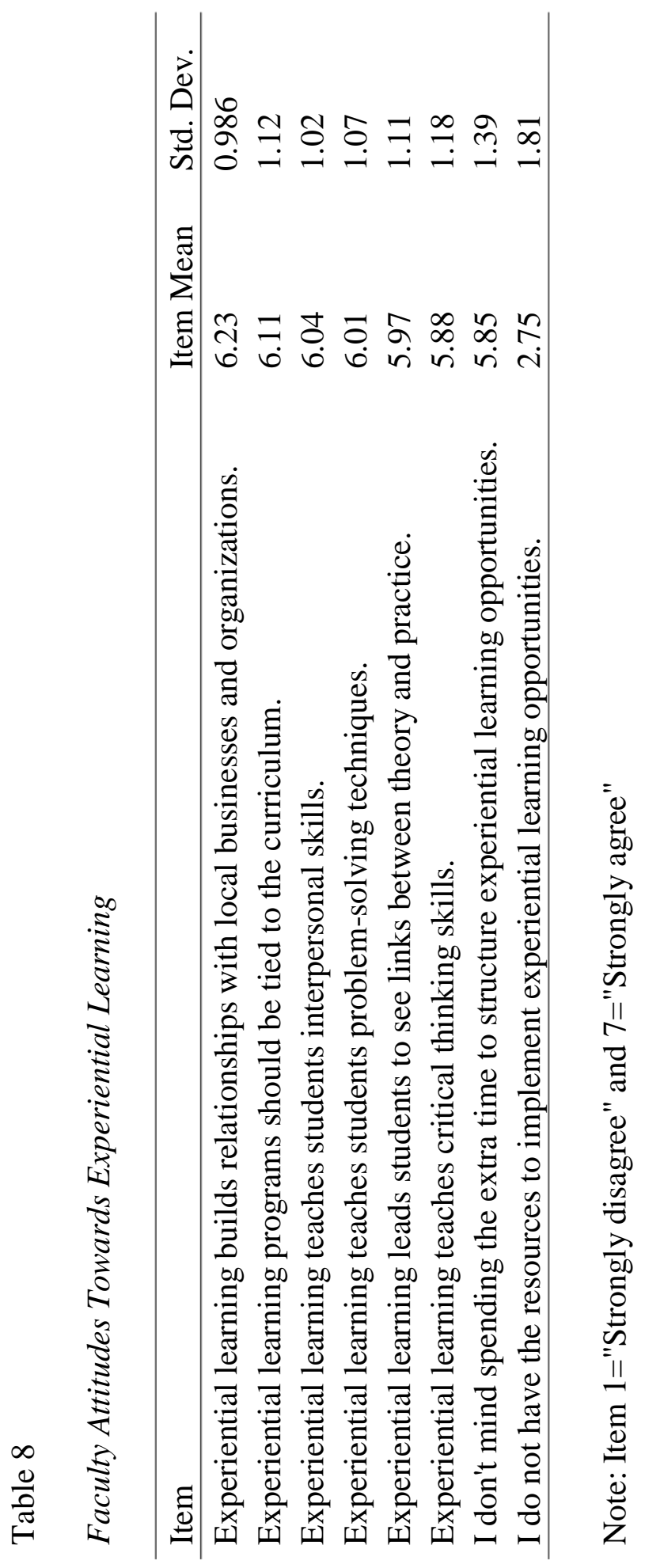


problem-solving skills, ability to link theory and practice, and critical thinking skills. Mean scores for those individual items ranged from 5.97 to 6.04, suggesting that faculty have favorable attitudes towards experiential learning techniques and their ability to have a positive impact student outcomes. Of the four items related to student learning outcomes, item 3, "Experiential learning teaches students interpersonal skills" had the highest mean score of 6.04 .

Of the eight items included, the item with the highest mean score overall (6.23) was item 1, which stated that "Experiential learning builds relationships with local businesses and organizations." $80.1 \%$ of faculty indicated that they "Strongly Agreed/Agreed" with this statement, by selecting either a 6 or 7 on the Likert scale. This finding aligns with the results from the previous question, which revealed that internship was the experiential learning technique that faculty found to be most effective in aiding student learning. If they view the internship experience of the student as the most effective, it is not surprising that they also view experiential learning as a vehicle for building relationships with local businesses and organizations, as that is inherently what the internship experience does.

Item 7 and 8 were used to determine respondent attitudes toward the facilitation of experiential learning. Item 7 asked respondents to rate how much they agreed with the statement, "I don't mind spending the extra time to structure experiential learning opportunities." While this item ranked lower, with a mean score of 5.85, it is still clear that faculty are generally willing to put in the time to create experiential learning opportunities for their students. Item 8 asked respondents to rate how much they agreed with the statement, "I do not have the resources to implement experiential learning 
opportunities." With a mean score of $2.75(\mathrm{SD}=1.81)$, this item provided the widest range of responses. While $58.8 \%$ of faculty said they either Strongly Disagreed/Disagreed with this statement by selecting a 1 or 2, 27.2\% of faculty said they either Agreed or Strongly Agreed with the statement by selecting a 5,6, or 7. This suggests that perhaps there is some variance in the amount of resources available to faculty in developing experiential learning opportunities.

The results from research question two, "What are the attitudes of faculty, as they relate to the application of experiential learning techniques and their impact on student learning?" support hypothesis two, which stated that faculty will generally respond positively towards experiential learning techniques and their ability to aide student learning.

\section{RQ 3: Impact of Academic and Professional Experience on Faculty Attitudes}

\section{Towards Experiential Learning}

The final research question asked, "In what ways, if any, do academic and professional experiences impact faculty attitudes towards the implementation of experiential learning techniques?" Based on prior research across the industry, the following hypotheses were developed: $\left(\mathrm{H}_{3 \mathrm{a}}\right)$ There will be differences among faculty responses based on prior educational experience, $\left(\mathrm{H}_{3 \mathrm{~b}}\right)$ there will be differences among faculty responses based on prior work experience in the sport industry, and $\left(\mathrm{H}_{3 \mathrm{c}}\right)$ there will be differences among faculty responses based on prior teaching experience.

In order to determine whether or not group differences exist for each hypothesis, a series of One-Way ANOVA tests and Independent T-tests were run. First, grouping variables were established for each demographic category related to the question. In 
response to $\mathrm{H}_{3 \mathrm{a}}$, survey instrument question 8 asked respondents to identify the school or program from which they received their terminal degree. When reporting the school or program from which they received their terminal degree, $43 \%(n=49)$ reported an education program, $37.7 \%(n=43)$ reported either a kinesiology or health sciences program, and the remaining $19.3 \%$ (22) reported a business and/or sport management program. Due to these results, three grouping categories were developed: "Education", "Kinesiology", and "Business". A one-way analysis of variance (ANOVA) was conducted to evaluate the relationship between terminal degree program and faculty attitudes towards experiential learning techniques. The independent variable, terminal degree program, included three categories (Education, Kinesiology, and Business). The dependent variable was the Likert Scale scores for question 3 on the survey, which included 8 items regarding both student learning outcomes and faculty facilitation of experiential learning techniques. The ANOVA was significant, $F_{(2,111)}=3.470, p=.035$, for one of the survey items, Item 5, which stated "Experiential learning leads students to see links between theory and practice". Post hoc comparisons (Bonferroni) found significant differences in the means between faculty who received their terminal degree from an Education program $(\mathrm{M}=6.27 ; \mathrm{SD}=.818)$ and faculty who received their degree from a Kinesiology/Health Sciences program $(M=5.75 ; S D=1.25)$. This finding suggests there is a more of a correlation with faculty who have a terminal degree from an education program and the statement "Experiential learning leads students to see links between theory and practice" than faculty who received a terminal degree from a Kinesiology and/or Health Sciences program. There were no additional significant ANOVAs related to terminal degree program. The results support $\mathrm{H}_{3 \mathrm{a}}$, which stated that 
there would be differences among faculty responses based on prior educational experience.

In response to $\mathrm{H}_{3 \mathrm{~b}}$, survey instrument question 9 asked respondents to specify the number of years they had worked full-time as a practitioner in the sport industry prior to becoming a faculty member. When reporting the number of years, $18.4 \%(n=25)$ said they had no experience working in the industry, while $33.9 \%(n=46)$ reported working 1 4 years, and $47.7 \%(n=65)$ reported over 5 years of experience working in the sport industry. For analysis purposes, the grouping variables will be referred to as "No Work Experience", “Some Work Experience”, and "Several Years Work Experience”. A oneway analysis of variance (ANOVA) was conducted to evaluate the relationship between years of sport industry experience and faculty attitudes towards experiential learning techniques. The independent variable, years of work experience, included three categories (No Work Experience, Some Work Experience, and Several Years Work Experience). The dependent variable was the Likert Scale scores for question 3 on the survey, which included 8 items regarding both student learning outcomes and facility facilitation of experiential learning techniques. The ANOVA was not significant for any of the survey items, therefore a Post hoc comparison (Bonferroni) was not needed to determine group differences. The results allow for the rejection of $\mathrm{H}_{3 \mathrm{~b}}$, which stated that there would be differences among faculty responses based on prior work experience in the sport industry. 
Table 9

One-Way Analysis of Variance of Attitudes Towards Experiential Learning by Terminal Degree Program

\begin{tabular}{|c|c|c|c|c|c|c|}
\hline Item & Source & $\mathrm{df}$ & SS & MS & $\mathrm{F}$ & $\mathrm{p}$ \\
\hline \multirow[t]{3}{*}{ RELATIONBUS } & Between groups & 2 & 0.942 & 0.471 & 0.486 & 0.617 \\
\hline & Within groups & 111 & 107.689 & 0.97 & & \\
\hline & Total & 113 & 108.632 & & & \\
\hline \multirow[t]{3}{*}{ INTSKILLS } & Between groups & 2 & 1.737 & 0.868 & 0.918 & 0.402 \\
\hline & Within groups & 111 & 105 & 0.946 & & \\
\hline & Total & 113 & 106.737 & & & \\
\hline \multirow[t]{3}{*}{ THEORYPRAC } & Between groups & 2 & 6.977 & 3.489 & 3.47 & 0.035 \\
\hline & Within groups & 111 & 111.593 & 1.005 & & \\
\hline & Total & 113 & 118.57 & & & \\
\hline \multirow[t]{3}{*}{ PROBSOLV } & Between groups & 2 & 1.745 & 0.872 & 0.761 & 0.469 \\
\hline & Within groups & 111 & 127.176 & 1.146 & & \\
\hline & Total & 113 & 128.921 & & & \\
\hline \multirow[t]{3}{*}{ CRITTHINK } & Between groups & 2 & 0.201 & 0.1 & 0.068 & 0.935 \\
\hline & Within groups & 111 & 164.826 & 1.485 & & \\
\hline & Total & 113 & 165.026 & & & \\
\hline \multirow[t]{3}{*}{ TIME } & Between groups & 2 & 0.678 & 0.339 & 0.202 & 0.817 \\
\hline & Within groups & 111 & 186.348 & 1.679 & & \\
\hline & Total & 113 & 187.026 & & & \\
\hline \multirow[t]{3}{*}{ CURRICULUM } & Between groups & 2 & 3.469 & 1.734 & 1.556 & 0.215 \\
\hline & Within groups & 111 & 123.689 & 1.114 & & \\
\hline & Total & 113 & 127.158 & & & \\
\hline \multirow[t]{3}{*}{ NORESOURCES } & Between groups & 2 & 0.298 & 0.149 & 0.047 & 0.954 \\
\hline & Within groups & 111 & 353.956 & 3.189 & & \\
\hline & Total & 113 & 354.254 & & & \\
\hline
\end{tabular}




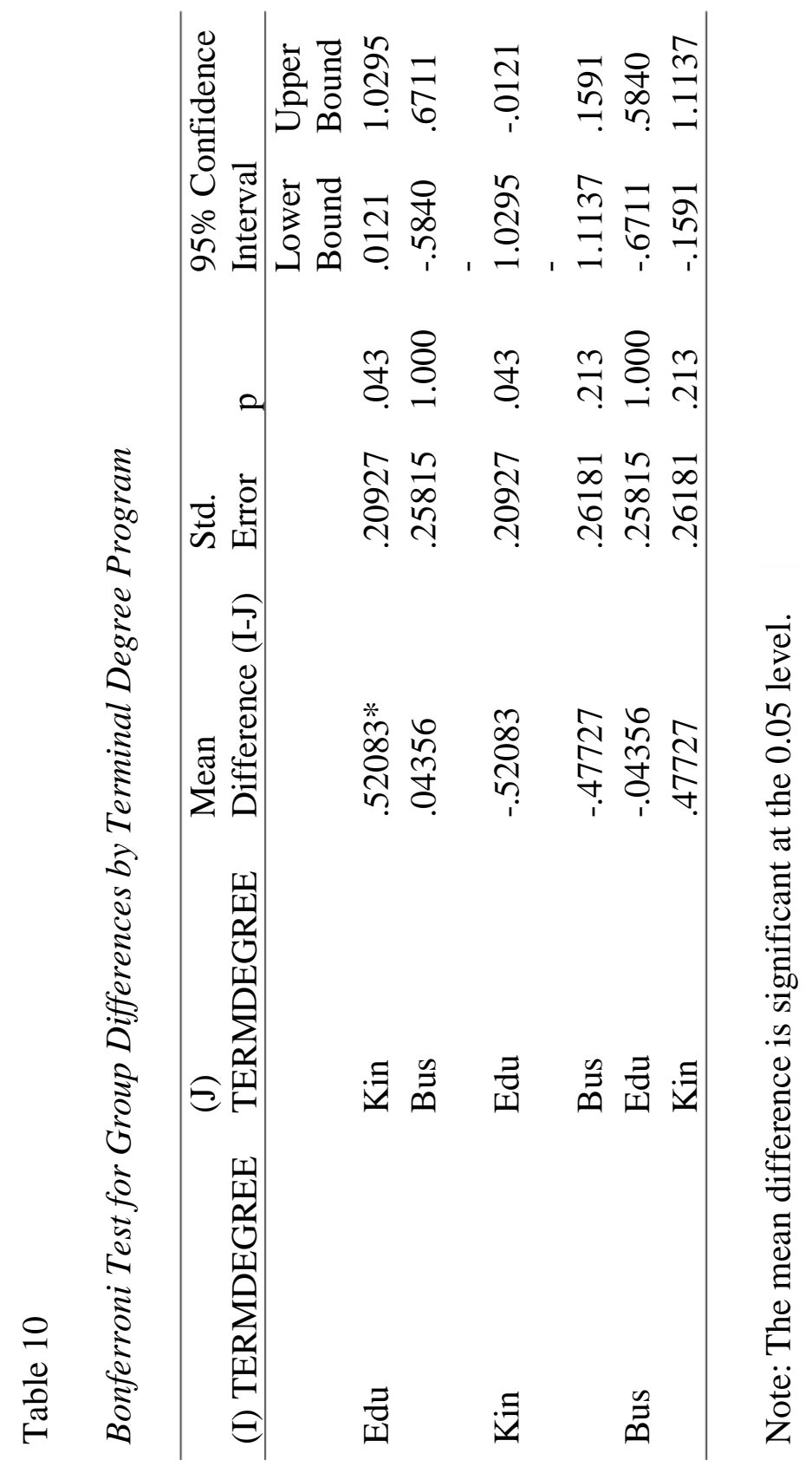


Table 11

One-Way Analysis of Variance of Attitudes Towards Experiential Learning by Years of Sport Industry Experience

\begin{tabular}{|c|c|c|c|c|c|c|}
\hline Item & Source & df & SS & MS & $\mathrm{F}$ & $\mathrm{p}$ \\
\hline \multirow[t]{3}{*}{ THEORYPRAC } & Between groups & 2 & 0.838 & 0.419 & 0.326 & 0.722 \\
\hline & Within groups & 133 & 170.898 & 1.285 & & \\
\hline & Total & 135 & 171.735 & & & \\
\hline \multirow[t]{3}{*}{ INTSKILLS } & Between groups & 2 & 0.067 & 0.034 & 0.032 & 0.969 \\
\hline & Within groups & 133 & 140.749 & 1.058 & & \\
\hline & Total & 135 & 140.816 & & & \\
\hline \multirow[t]{3}{*}{ PROBSOLV } & Between groups & 2 & 2.413 & 1.206 & 1.045 & 0.355 \\
\hline & Within groups & 133 & 153.558 & 1.155 & & \\
\hline & Total & 135 & 155.971 & & & \\
\hline \multirow[t]{3}{*}{ CRITTHINK } & Between groups & 2 & 3.796 & 1.898 & 1.349 & 0.263 \\
\hline & Within groups & 133 & 187.079 & 1.407 & & \\
\hline & Total & 135 & 190.875 & & & \\
\hline \multirow[t]{3}{*}{ TIME } & Between groups & 2 & 4.261 & 2.13 & 1.095 & 0.338 \\
\hline & Within groups & 133 & 258.798 & 1.946 & & \\
\hline & Total & 135 & 263.059 & & & \\
\hline \multirow[t]{3}{*}{ CURRICULUM } & Between groups & 2 & 1.223 & 0.611 & 0.478 & 0.621 \\
\hline & Within groups & 133 & 170.123 & 1.279 & & \\
\hline & Total & 135 & 171.346 & & & \\
\hline \multirow[t]{3}{*}{ RELATIONBUS } & Between groups & 2 & 2.58 & 1.29 & 1.332 & 0.267 \\
\hline & Within groups & 133 & 128.803 & 0.968 & & \\
\hline & Total & 135 & 131.382 & & & \\
\hline \multirow[t]{3}{*}{ NORESOURCES } & Between groups & 2 & 8.96 & 4.48 & 1.365 & 0.259 \\
\hline & Within groups & 133 & 436.54 & 3.282 & & \\
\hline & Total & 135 & 445.5 & & & \\
\hline
\end{tabular}




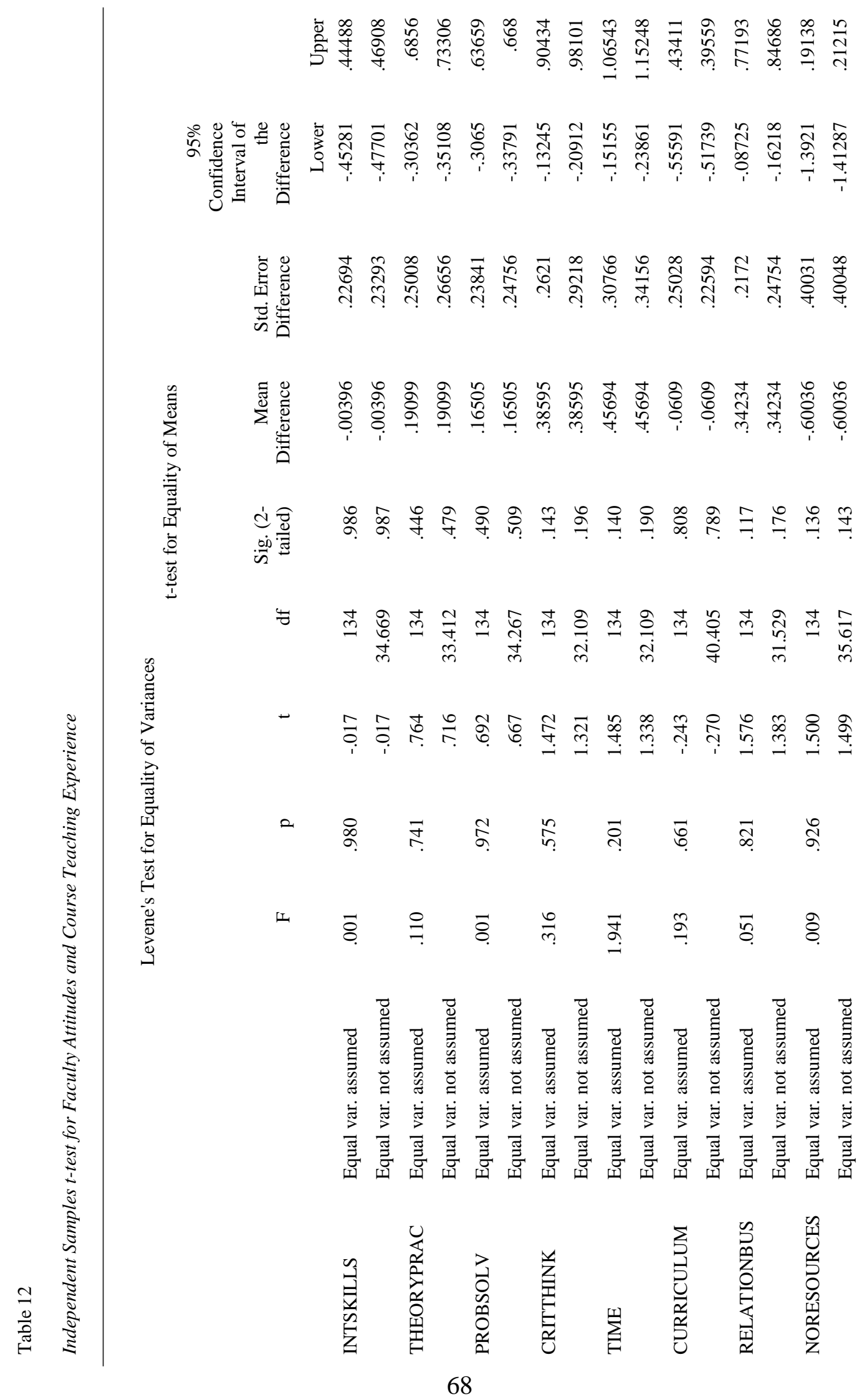


In response to $\mathrm{H}_{3 c}$, survey instrument question 5 asked respondents to specify the number of years they had been teaching in sport management. When reporting the number of years, more than half of the respondents $(61 \%, n=83)$, reported 6 or more years of teaching experience, while the remaining $39 \%(n=53)$ reported 5 years or fewer. For analysis purposes, the grouping variables will be referred to as "Experienced Faculty" and "Early Career Faculty". Because there were just two grouping variables for this item, an independent t-test was conducted in order to evaluate the difference in group means for experienced faculty and early career faculty in regards to their attitudes towards experiential learning techniques. The dependent variables were the Likert Scale scores for question 3 on the survey, which included 8 items regarding both student learning outcomes and facility facilitation of experiential learning techniques. There were no significant differences between the two groups for any of the testing variables. The results allow for the rejection of $\mathrm{H}_{3 \mathrm{c}}$, which stated that there would be differences among faculty responses based on prior teaching experience in sport management.

An additional test was run to determine whether or not faculty attitudes towards experiential learning were impacted by individual course load. An independent samples ttest was conducted to evaluate the difference in the group means for faculty who identified as having a "light" course load by teaching 1-2 courses per semester, and faculty who identified as having a "heavy" course load by teaching 3 or more courses per semester. In regards to teaching load per semester, $54.4 \%(\mathrm{n}=74)$ reported teaching 1 to 2 courses, while $45.5 \%(n=62)$ reported teaching 3 or more courses per semester. For analysis purposes, the grouping variables will be referred to as "Light Teaching Load" and "Heavy Teaching Load". The dependent variables were the Likert Scale scores for 


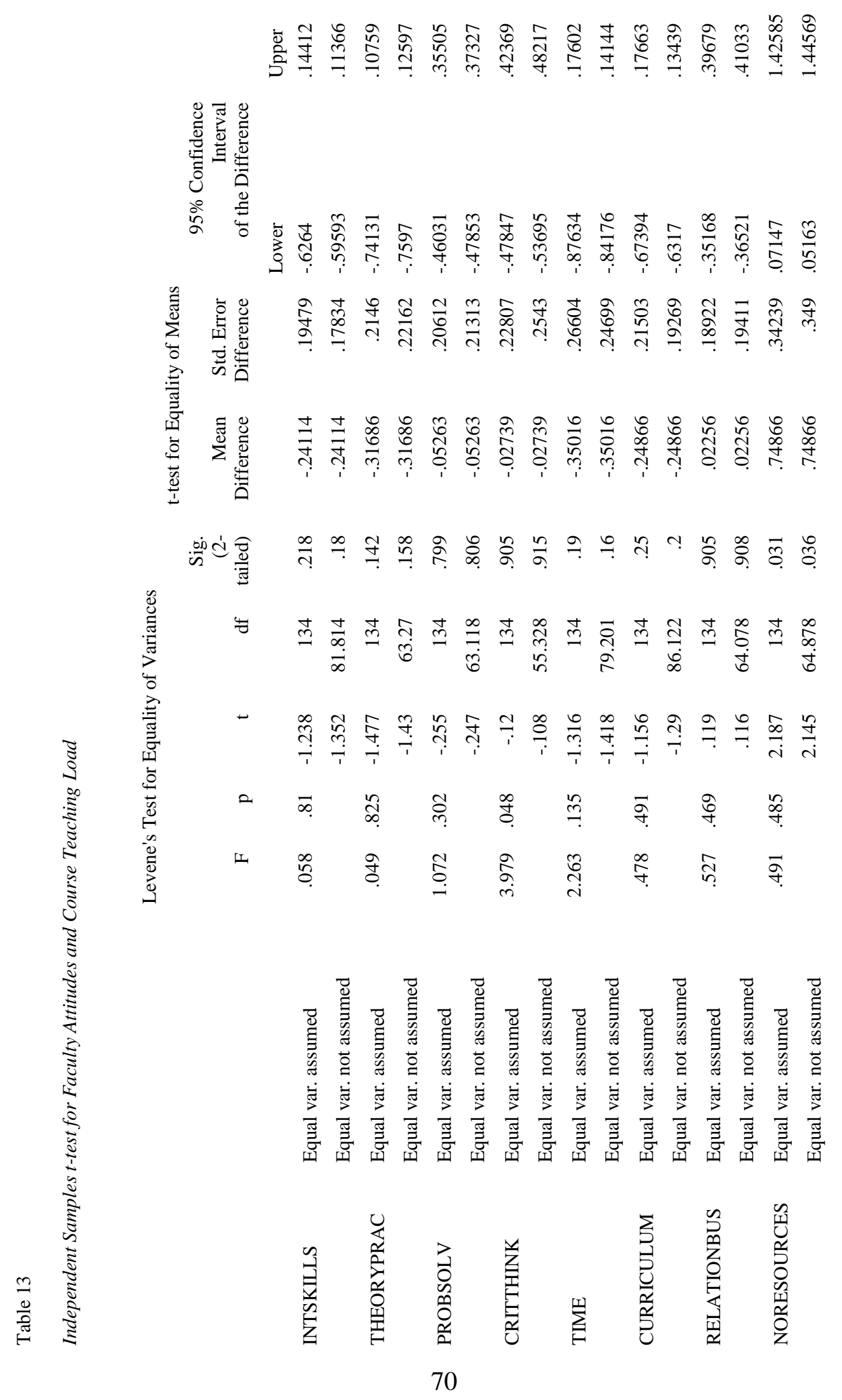


question 3 on the survey, which included 8 items regarding both student learning outcomes and facility facilitation of experiential learning techniques.

There is a significant difference between faculty with a light teaching load $(\mathrm{M}=5.63, \mathrm{SD}=1.49)$ and faculty with a heavy teaching load $(\mathrm{M}=6.11, \mathrm{SD}=1.22), t(134)=-$ 2.010, $\mathrm{p}=.046$, in relation to Item 5, which stated, "I don't mind spending the extra time to structure experiential learning opportunities." Specifically, this result suggests there is a coorelation with teaching load and a faculty member's willingness to spend the extra time to structure experiential learning opportunities for their students. This could be explained by the fact that faculty teaching 3 or more classes per semester tend to have fewer scholarly requirements than faculty teaching just 1 to 2 courses. There is also a significant difference between faculty with a light teaching load $(\mathrm{M}=3.06, \mathrm{SD}=1.76)$ and faculty with a heavy teaching load $(\mathrm{M}=2.37, \mathrm{SD}=1.81), t(134)=2.261, \mathrm{p}=.025$, in relation to Item 8, which stated "I do not have the resources to implement experiential learning opportunities." Specifically, this result suggests there is a correlation with teaching load and the amount of resources faculty have to implement experiential learning opportunities. While the mean scores for both still skewed towards disagreement, it is surprising to see that faculty with a light teaching load were more likely to agree with this statement. This could be explained by the fact that faculty with light teaching loads may tend to be housed in research-based universities, and thus may have fewer resources related to curriculum development on campus at their disposal.

Although years of teaching has no impact on faculty attitudes towards experiential learning, it is clear after analysis that the size of course load does play a role in how 
faculty view the application of experiential learning techniques, specifically when it comes to the time it takes to implement and the resources available.

\section{Summary}

The purpose of this study was to investigate the application of experiential learning practices across sport management programs. Sport management faculty were surveyed about their usage of experiential learning techniques specific to the sport management field (Foster \& Dollar, 2010). They were also asked about their attitudes towards experiential learning as they relate to the application of experiential learning techniques and their impact on student learning.

Results showed that the overwhelming majority of sport management faculty are utilizing some form of experiential learning both inside and outside of the classroom. Particularly, a large percentage of faculty identified as "Adopters" of both classroombased experiential learning and internship experiences. Faculty held favorable attitudes towards experiential learning as a practice, particularly in its ability to help students engage with local sport organizations and businesses. Finally, more in depth analysis revealed some significant group differences based on the terminal degree program and the course teaching load of faculty. More in-depth discussion of the results, along with some conclusions and recommendations for future research can be found in Chapter V. 


\section{CHAPTER V}

\section{SUMMARY, CONCLUSIONS, AND RECOMMENDATIONS}

This chapter provides a synthesized discussion of the research study and is broken up into the following sections: a summary of the study, a discussion of conclusions based on the findings, significance of the study findings, limitations of the study, and recommendations for future research.

\section{Summary of the Research}

The implementation of experiential learning practices by faculty has been a growing trend across institutions of higher learning as millennial students have come to expect an engaging and interactive learning environment (Mangold, 2007). These practices have further been encouraged by higher education administrators, particularly due to contemporary research that suggests that student exposure to experiential education positively impacts student learning outcomes, as well as persistence and retention rates (Eyler, 2009; Pierson \& Troppe, 2010; The National Center for Public Policy and Higher Education, 2008).

In addition to widespread acceptance of experiential learning on college campuses, research suggests that practitioners in the sport industry continually rate applied, field experiences as crucial to effective sport management education programs (King, 2009; Petersen \& Pierce, 2009; Stier \& Schneider, 2000). Industry practitioners have also contended that students in sport management programs don't get enough real- 
world experience or practice prior to entering the field, resulting in a preference to hire someone with experience over a degree in sport management (Cuban, 2014; Dolich, 2004; King, 2009). As sport industry practitioners seek out employees with more applied experience each year, it becomes even more important for students to have experiential learning opportunities inside and outside of the classroom.

There is evidence to suggest some level of acceptance of experiential learning practices within the academic field of sport management. The Commission on Sport Management Accreditation (COSMA) has identified experiential learning as an integral element to be included in sport management curriculum (COSMA, 2016). In addition, with the 2007 advent of the Sport Management Education Journal (SMEJ), a number of sport management scholars have examined experiential learning outcomes within individual classroom environments (Bower, 2013; Irwin, Sutton, \& McCarty, 2007; Miller, Meaney, \& Podlug, 2012; Pauline, 2013; Turesky \& Gallagher, 2011; Southall, Nagel, LeGrande, and Han, 2003). And while Eagleman \& McNary's (2010) content analysis of undergraduate sport management programs suggests the majority of sport management programs now require an internship experience of their students, there is little information regarding the implementation of other experiential learning practices by sport management faculty.

Parkhouse (2001) defined two categories of experiential learning activities within sport management programs: discrete and non-discrete. Discrete experiential learning activities are experiences that occur separate from the on-campus educational experience, and non-discrete experiential learning activities are experiences that occur as an extension of an on-campus learning activity. In their book titled Experiential Learning in 
Sport Management, Foster and Dollar (2010) developed the Foster Five-Step Experiential Learning Process Model, which encourages sport management programs to provide experience both inside and outside of the classroom to students prior to applying for their first full-time position in the sport industry. The five steps of the model include: volunteer exploration, apprenticeship, classroom, practicum elective, and culminating internship. Each step within the model was utilized as a variable within the current study.

The purpose of this study was to assess the application of experiential learning practices across sport management programs, specifically by investigating faculty application of experiential learning practices, faculty attitudes as they relate to the application of experiential learning practices, and the impact of academic and professional experiences on faculty attitudes towards experiential learning practices. The study was designed to address the following research questions:

\section{Research Questions}

$\mathrm{R}_{1}$ : Which experiential learning techniques are utilized most often by sport management faculty across sport management programs?

$\mathrm{R}_{2}$ : What are the attitudes of faculty, as they relate to the application of experiential learning techniques and their impact on student learning?

$\mathrm{R}_{3}$ : In what ways, if any, do academic and professional experiences impact faculty attitudes towards the implementation of experiential learning techniques?

\section{Hypotheses}

Based on previous literature in the areas of experiential learning and sport management pedagogy outlined in Chapter II, the following research hypotheses were proposed: 
$\mathrm{H}_{1 \mathrm{a}}$ : The internship will be the most widely reported experiential learning technique across sport management programs, while volunteer exploration and classroom-based techniques will also be widely reported by faculty (Eagleman \& McNary, 2010; Sax \& Astin, 1997; Bennett, Henson, \& Drane, 2003).

$\mathrm{H}_{2 \mathrm{a}}$ : Faculty will generally respond positively towards experiential learning techniques and their ability to aide student learning (Wilson, 2008; Label, Danylchuk, \& Millar, 2015).

$\mathrm{H}_{3 \mathrm{a}}$ : There will be differences among faculty responses based on prior educational experience (Geurin-Eagleman \& McNary, 2014).

$\mathrm{H}_{3 \mathrm{~b}}$ : There will be differences among faculty responses based on prior work experience in the sport industry (Pierson \& Troppe, 2010).

$\mathrm{H}_{3 c}$ : There will be differences among faculty responses based on prior teaching experience (Eyler, 2009).

Information from this study can be used to help sport management educators understand the current state of experiential learning application across sport management programs. Up to this point, a singular study has yet to provide an in-depth analysis of the widespread application of experiential learning practices across the academic field of sport management. In addition, no studies have examined sport management faculty attitudes towards the use of experiential learning practices and their impact on student learning.

Participants in this study were identified as sport management faculty across the United States. They were contacted via E-mail through the North American Society for 
Sport Management (NASSM) list-serv, and asked to participate in the study through an online survey. A survey instrument was adapted from a previously tested questionnaire that was utilized to measure service learning across marketing departments in higher education (McIntyre, Webb, \& Hite, 2005). The newly adapted survey was titled the Experiential Learning in Sport Management Survey (ELSM). Through the survey instrument, participants answered questions regarding their own application of experiential learning practices, as well as their attitudes towards experiential learning and its impact on student learning. Once the data was collected and organized, a variety of both descriptive and more advanced statistical tests were completed in order to address the research questions at hand.

Descriptive statistics provided information about the participants and provided insight into faculty application or usage of specific experiential learning techniques. Analysis of Variance (ANOVA) testing and independent samples t-tests were conducted in order to measure variability among the following independent variables: prior teaching experience, prior industry experience, and terminal degree program of study. These tests allowed for analysis into whether or not prior faculty experience would have an impact on their attitudes toward experiential learning.

\section{Conclusions}

The following section will include a discussion of conclusions based on the findings addressed in Chapter IV. Attempts to connect the conclusions back to the literature are made throughout. 


\section{RQ 1: Faculty Usage of Experiential Learning Techniques}

Based on prior research that indicated a heavy emphasis on the internship experience (Eagleman \& McNary, 2010; Foster \& Dollar, 2010), volunteer exploration (Bennett, Henson, \& Drane, 2003; Sax \& Astin, 1997; Valerius, et al., 1998), and classroom-based techniques (Foster \& Dollar, 2010; Irwin, Sutton, \& McCarty, 2007; Pauline, 2013; Southall, Nagel, LeGrande, and Han, 2003), the following hypothesis was developed: The internship will be the most widely reported experiential learning technique across sport management programs, while volunteer exploration and classroom-based techniques will also be widely reported by faculty. While $70.6 \%$ of respondents were "Adopters" of the culminating internship, classroom-based experiential learning was actually the technique with the most "Adopters" at $83.1 \%$. Additionally, $21.3 \%$ of respondents identified as "Non-Users" of culminating internship. One likely explanation for this result relates to the formalized structure of sport management internship programs, in which one or two faculty members are designated as the "field experience coordinator" for all of the interns within the program (Schneider \& Steir, 2006). This structure could explain why there are so many "Non-Users" of the culminating internship. Faculty members simply may not have access to the internship program if they are not one of the designated field experience coordinators. On the contrary, it is assumed that all faculty who teach at least one course have access to a classroom, which means they can utilize classroom-based experiential learning techniques.

Regardless of the ranking based on "Adopters", the internship has clearly been adopted by a majority of respondents, partially confirming the hypothesis from the first 
research question. This is a positive finding, and confirms prior studies which suggest that the field of sport management academic continues to embrace the internship as a core tenant of a sport management education.

As previously stated, classroom-based experiential learning had the highest percentage of "Adopters" in the study, with $83.1 \%$ of respondents stating that they use the method on a regular, ongoing basis. This technique also had the lowest percentage of "Non-Users", with just $5.9 \%$ of respondents stating they never use classroom-based experiential techniques. This finding is consistent with much of the literature, which suggests that more and more faculty are incorporating project-based experiential learning techniques into their classrooms (Foster \& Dollar, 2010; Irwin, Sutton, \& McCarty, 2007; Pauline, 2013; Southall, Nagel, LeGrande, and Han, 2003). This is a positive finding, as it implies that a large majority of sport management faculty have moved away from sole utilization of traditional teaching methods in order to incorporate more experiential methods. While this study didn't examine the extent to which faculty are implementing classroom-based experiences, nor specific classroom-based techniques via a survey item, several respondents provided information about the types of classroom-based techniques they are utilizing in the comments section at the end of the survey. Examples include: case studies, client-based projects, and sport event planning and facilitation. This information further confirms the literature, which showcases a wide variety of these same classroom-based experiences in individual classrooms.

Another conclusion from the first research question relates to volunteer exploration. Less than half of respondents (46.3\%) identified as "Adopters" of volunteer exploration, with $20.5 \%$ identifying as "Non-Users". This result challenges the present 
literature, which suggested that volunteer exploration, and/or service learning, is widely adopted across both institutions of higher learning (Sax \& Astin, 1997) and sport management programs specifically (Bennett, Henson, \& Drane, 2003; Valerius, et al., 1998). Interestingly, nearly a quarter (23.5\%) of respondents identified as "Triers", which means they have tried the technique once or twice in the past, but are not currently implementing it. This could suggest a shift in how sport management faculty view volunteer exploration as an experiential learning technique. More in-depth research is required to further explore this potential shift and some suggestions for future research are provided in a later section.

In regards to apprenticeship, only $24.6 \%$ of respondents identified as "Adopters", while nearly half of respondents (47.8\%) identified as "Non-Users". The low usage rate of apprenticeship as an experiential learning technique is not terribly surprising considering the literature related to sport industry practitioner perceptions of graduate preparedness. That literature suggests that sport industry practitioners often undervalue sport management programs due to their inability to properly train students in areas of sales, communication, and leadership (Cawley, 1999; Cuban, 2014; DeLuca \& Braunstein-Minkove, 2016; Dolich, 2004; King, 2009). The lack of apprenticeship application should be concerning for those in sport management academia. Competition within the sport industry continues to grow, along with the number of undergraduate sport management programs, leading to a highly competitive job market, one in which sport management graduates are often competing with non-sport management majors as well. Historically, it has likely never been more important for sport management students to possess a range of applied skill-sets prior to entering the job market. Attempts should 
be made my faculty and program directors to ensure students are exposed to apprenticeship experiences, either in the classroom, with local sports organizations, or in a more formalized training program like Major League Soccer's (MLS) National Sales Center, where students are enrolled into a highly specialized training program where they learn principles of selling through role play and improvisation, and receive exclusive software training from Ticketmaster (Major League Soccer National Sales Center, 2016).

One final conclusion drawn in reference to faculty usage of experiential learning techniques is that the three techniques that are likely to occur earliest in a student's degree program (apprenticeship, volunteer exploration, and practicum elective), and therefore give them early exposure to the sport industry, are also the three techniques least likely to be adopted by faculty in this study, with fewer than $50 \%$ of respondents identifying as "Adopters" of each technique respectively. This conclusion is counter to the literature, which repeatedly confirms that students benefit from both early exposures to experiential learning opportunities, and multiple experiential learning opportunities throughout their college experience (DeLuca and Braunstein-Minkove, 2016; Foster \& Dollar, 2010; Hayes, 2015). While faculty may not have the time nor the resources to implement all of these techniques, attempts should be made at the program level to facilitate a formalized practicum course that is required of students early in their degree program (freshman or sophomore year). In addition, program directors and/or field experience coordinators can utilize already existing relationships with local sports organizations to facilitate apprenticeship programs as potential independent study opportunities for students. 
Generally speaking, the results of this study suggest there is widespread application of experiential learning techniques by sport management faculty. Specifically, classroom-based experiences and internship experiences are being adopted at very high levels, with a majority of respondents identifying as "Adopters" of both. Both apprenticeship and practicum elective have high "Non-User" adoption rates, which is reflective of the literature. Finally, fewer than half of respondents are "Adopters" of volunteer exploration, despite the literature's suggestions that it is widely used across the field. Each of these conclusions add to the existing body of literature related to experiential learning, while generating new questions for future study.

\section{RQ 2: Faculty Attitudes Towards Experiential Learning}

Based on an increase in the amount of scholarly work geared towards experiential learning in the field over the last decade (Sport Management Education Journal, 2016), the following hypothesis was developed: Faculty will generally respond positively towards experiential learning techniques and their ability to aide student learning. In order to determine faculty attitudes, two measurement items were used. Respondents were first asked to choose the experiential learning technique they believe is "most effective" in aiding student learning. Next, they were asked about their attitudes towards experiential learning through a series of Likert-Scale questions.

Of the five techniques provided by Foster and Dollar (2010), internship was ranked by a majority of respondents as most effective, with $58.1 \%(\mathrm{n}=79)$ choosing it. Classroom-based experiential learning came in second, with $18.4 \%(\mathrm{n}=25)$ of respondents ranking it most effective. As discussed in relation to the previous question, faculty were more likely to be "Adopters" of classroom-based techniques than any other technique, 
including the internship, which offers somewhat of a disconnect from the findings related to this question, which suggest that faculty attitudes towards are more favorable toward the internship experiences. Again, one likely explanation for this result relates to the formalized structure of sport management internship programs, in which one or two faculty members are designated as the "field experience coordinator" for all of the interns (Schneider \& Steir, 2006). Faculty members simply may not have access to the internship program if they are not one of the designated field experience coordinators. That doesn't mean they don't value them or consider them to be effective in aiding student learning. In fact, many respondents provided support for this sentiment in the comments section of this survey item, claiming that while they may not personally oversee the internship experience, they still value that experience highly for their students. The internship is clearly viewed as the most effective experiential learning technique to aide student learning, partially confirming the hypothesis from the second research question, and thus is consistent with much of the literature related to high levels of internship adoption across sport management academia. Moving forward, a qualitative study could offer more in-depth insight into how faculty view the internship experience.

Of the five techniques, volunteer exploration was the least likely to be identified as the "most effective" in aiding student learning, with just $1.5 \%(\mathrm{n}=2)$ of respondents selecting it. This finding was surprising, as once again, the literature suggests not only that sport management faculty are utilizing volunteer exploration or service learning at high rates (Bennett, Henson, \& Drane, 2003; Valerius, et al., 1998), but also that it is viewed as an effective learning tool by faculty across higher education (Sax \& Astin, 1997). In addition to positive learning outcomes of students, faculty tend to support the 
use of service learning, as evidenced by a national survey in which $80 \%$ of faculty across academic areas said they believed students should participate in some kind of servicerelated activity (Sax \& Astin, 1997). In conjunction with the results from question one in relation to volunteer exploration, which suggested lower than expected adoption rates, it is evident that the way sport management faculty view volunteer exploration or service learning is changing.

In order to further determine faculty attitudes towards experiential learning more generally, respondents were asked to respond to a series of eight Likert scale questions. The items listed included statements regarding both student learning outcomes and faculty facilitation of experiential learning methods. Specifically, items 3, 4, 5, and 6 were used to determine respondent attitudes of experiential learning related to student learning outcomes, including such measures as interpersonal skills, problem-solving skills, ability to link theory and practice, and critical thinking skills. Mean scores for those individual items ranged from 5.97 to 6.04 , suggesting that faculty have favorable attitudes towards experiential learning techniques and their ability to have a positive impact student outcomes, which confirms the hypothesis for question two, along with the prior literature suggesting that faculty tend to have favorable attitudes towards experiential learning (Eyler, 2009; Pierson \& Troppe, 2010).

Of the eight items included, the item with the highest mean score overall (6.23) was "Experiential learning builds relationships with local businesses and organizations." $80.1 \%$ of faculty indicated that they "Strongly Agreed/Agreed" with this statement, by selecting either a 6 or 7 on the Likert scale. This finding aligns with the results from the previous question, which revealed that internship was the experiential learning technique 
that faculty found to be most effective in aiding student learning. If they view the internship experience of the student as most effective, it is not surprising that they also view experiential learning as a vehicle for building relationships with local businesses and organizations.

Another item asked respondents to rate how much they agreed with the statement, "I do not have the resources to implement experiential learning opportunities." With a mean score of $2.75(\mathrm{SD}=1.81)$, this item provided the widest range of responses. While $58.8 \%$ of faculty said they either Strongly Disagreed/Disagreed with this statement by selecting a 1 or 2, 27.2\% of faculty said they either Agreed or Strongly Agreed with the statement by selecting a 5,6 , or 7 . This suggests that perhaps there is some variance in the number of resources or support available to faculty in developing experiential learning opportunities. Specifically, group differences existed for faculty based on teaching load. Faculty with a light teaching load (1-2 courses per semester) were more inclined to agree with the statement, "I do not have the resources to implement experiential learning opportunities" than faculty with a heavy teaching load ( 3 or more courses per semester). More discussion on this, and other group differences, can be found in the next section.

Respondents were asked to rate how much they agreed with the statement, "Experiential learning programs should be tied to the curriculum." With a mean score $6.11(\mathrm{SD}=1.12)$, this item was ranked second highest by faculty, suggesting that faculty strongly believe that experiential learning should have a place within or across sport management curriculum. This finding is consistent with the literature related to the historical development of sport management curriculum, particularly COSMA's 
inclusion of an experiential learning component within its most recent accreditation manual (COSMA, 2016). Prior to this study, the extent to which faculty agreed with this sentiment was unclear, as just 45 sport management programs were currently accredited under COSMA standards. In addition, with the 2007 advent of the Sport Management Education Journal (SMEJ), a handful of sport management scholars have examined experiential learning outcomes within individual classroom environments and found positive learning outcomes (Bower, 2013; Irwin, Sutton, \& McCarty, 2007; Miller, Meaney, \& Podlug, 2012; Pauline, 2013; Turesky \& Gallagher, 2011; and Southall, Nagel, LeGrande, and Han, 2003), further evidence that the current study's finding is consistent with the existing literature.

Overall, these findings confirm the hypothesis for the second research question; that sport management faculty will have favorable attitudes towards experiential learning techniques and their ability to aide student learning.

\section{RQ 3: Impact of Academic and Professional Experience on Faculty Attitudes}

\section{Towards Experiential Learning}

Based on prior research across the industry, as well as Kolb's experiential learning theory (1989), the following hypotheses were developed: $\left(\mathrm{H}_{3 \mathrm{a}}\right)$ There will be differences among faculty responses based on prior educational experience, $\left(\mathrm{H}_{3 b}\right)$ there will be differences among faculty responses based on prior work experience in the sport industry, and $\left(\mathrm{H}_{3 \mathrm{c}}\right)$ there will be differences among faculty responses based on prior teaching experience. As previously discussed in the theoretical framework, Kolb's theory is based on a holistic model of learning that is derived from one's own experiences (Kolb \& Kolb, 2009). Because this particular study sought to analyze the usage of experiential 
learning techniques of sport management faculty, it is pertinent to consider that their own prior experiences could have an impact on how they use and view experiential learning. In order to determine whether or not group differences exist for each hypothesis, a series of One-Way ANOVA tests and Independent T-tests were run.

Group Differences Based on Terminal Degree Program. In response to $\mathrm{H}_{3 a}$, survey instrument question 8 asked respondents to identify the school or program from which they received their terminal degree. When reporting the school or program from which they received their terminal degree, $43 \%(n=49)$ reported an education program, $37.7 \%(\mathrm{n}=43)$ reported either a kinesiology or health sciences program, and the remaining 19.3\% (22) reported a business and/or sport management program. Three grouping categories were developed: "Education", "Kinesiology", and "Business" and a one-way analysis of variance (ANOVA) was conducted to evaluate the relationship between terminal degree program and faculty attitudes towards experiential learning techniques.

The ANOVA was significant, $F_{(2,111)}=3.470, p=.035$, for one of the survey items, Item 5, which stated "Experiential learning leads students to see links between theory and practice". Post hoc comparisons (Bonferroni) found significant differences in the means between faculty who received their terminal degree from an Education program and faculty who received their degree from a Kinesiology/Health Sciences program. Further exploration revealed that there is a correlation with a faculty member's terminal degree program and attitude toward experiential learning and its ability to help link theory and practice. This finding is consistent with the literature. In their study of sport management doctoral students' career expectations, Geurin-Eagleman and McNary (2014), found that less than a quarter of sport management doctoral students (24.7\%) had 
taken a pedagogy course through their doctoral program, and only $18.5 \%$ had received guidance from their campus teaching and learning center. Not surprisingly, doctoral students within education programs are likely to be exposed to many more classes on pedagogy and/or curriculum development, and thus are more likely to have a better grasp on the linking of theory and practice across curriculum.

There were no other significant ANOVAs related to terminal degree program. Although minimal, with only one out of eight of the items revealing group differences, the result above does support $\mathrm{H}_{3 \mathrm{a}}$, which stated that there would be differences among faculty responses based on prior educational experience.

Group Differences Based on Prior Educational Experience. In response to $\mathrm{H}_{3 \mathrm{c}}$, survey instrument question 5 asked respondents to specify the number of years they had been teaching in sport management. When reporting the number of years, more than half of the respondents $(61 \%, \mathrm{n}=83)$, reported 6 or more years of teaching experience, while the remaining 39\% ( $\mathrm{n}=53$ ) reported 5 years or fewer. For analysis purposes, the grouping variables will be referred to as "Experienced Faculty" and "Early Career Faculty". Because there were just two grouping variables for this item, an independent t-test was conducted in order to evaluate the difference in group means for experienced faculty and early career faculty in regards to their attitudes towards experiential learning techniques.

There were no significant differences between the two groups for any of the testing variables. This result allows for the rejection of $\mathrm{H}_{3 c}$, which stated that there would be differences among faculty responses based on prior teaching experience in sport management. This finding is not necessarily consistent with the literature, which suggests that teachers tend to gain more confidence in their ability to teach and further, implement 
experiential learning techniques, after several years of experience in the classroom (Eyler, 2009; Pierson \& Troppe, 2010). Based on this assumption, the expected finding would have been to see that "Experienced Faculty" would have more favorable attitudes towards experiential learning than "Early Career Faculty". It is possible that Early Career Faculty have been more exposed to experiential learning as a student, and thus have a unique appreciation and understanding of experiential learning, despite not having much experience implementing it.

While this finding allows for the rejection of $\mathrm{H}_{3 c}$, it does support the overall hypothesis for research question two, which predicted that faculty would have generally favorable attitudes towards experiential learning and its ability to impact student learning.

Group Differences Based on Teaching Course Load. In addition to examining group differences based prior faculty educational and work experiences, an additional test was run to determine whether or not faculty attitudes towards experiential learning were impacted by individual course load. An independent samples t-test was conducted to evaluate the difference in the group means for faculty who identified as having a "light" course load by teaching 1-2 courses per semester, and faculty who identified as having a "heavy" course load by teaching 3 or more courses per semester. In regards to teaching load per semester, $54.4 \%(\mathrm{n}=74)$ reported teaching 1 to 2 courses, while $45.5 \%(\mathrm{n}=62)$ reported teaching 3 or more courses per semester. For analysis purposes, the grouping variables will be referred to as "Light Teaching Load" and "Heavy Teaching Load".

There was a significant difference between faculty with a light teaching load $(\mathrm{M}=5.63, \mathrm{SD}=1.49)$ and faculty with a heavy teaching load $(\mathrm{M}=6.11, \mathrm{SD}=1.22), t(134)=-$ $2.010, \mathrm{p}=.046$, in relation to Item 5 , which stated, "I don't mind spending the extra time 
to structure experiential learning opportunities." Specifically, this result suggests there is a coorelation with teaching load and a faculty member's willingness to spend the extra time to structure experiential learning opportunities for their students. This could be explained by the fact that faculty teaching 3 or more classes per semester tend to have fewer scholarly requirements and/or administrative duties than faculty teaching just 1 to 2 courses. There is also a significant difference between faculty with a light teaching load $(\mathrm{M}=3.06, \mathrm{SD}=1.76)$ and faculty with a heavy teaching load $(\mathrm{M}=2.37, \mathrm{SD}=1.81), t(134)=$ $2.261, p=.025$, in relation to Item 8 , which stated "I do not have the resources to implement experiential learning opportunities." Specifically, this result suggests there is a correlation with teaching load and the amount of resources faculty have to implement experiential learning opportunities. While the mean scores for both still skewed towards disagreement, it is surprising to see that faculty with a light teaching load were more likely to agree with this statement. This could be explained by the fact that faculty with light teaching loads may tend to be housed in research-based universities, and thus may have fewer resources related to teaching and curriculum development at their disposal.

\section{Group Differences Based on Prior Work Experience in the Sport Industry. In}

response to $\mathrm{H}_{3 \mathrm{~b}}$, survey instrument question 9 asked respondents to specify the number of years they had worked full-time as a practitioner in the sport industry prior to becoming a faculty member. When reporting the number of years, $18.4 \%(n=25)$ said they had no experience working the industry, while $33.9 \%(n=46)$ reported working $1-4$ years, and $47.7 \%(n=65)$ reported over 5 years of experience working in the sport industry. For analysis purposes, the grouping variables will be referred to as "No Work Experience", "Some Work Experience", and "Several Years Work Experience" and a one-way analysis 
of variance (ANOVA) was conducted to evaluate the relationship between years of sport industry experience and faculty attitudes towards experiential learning techniques.

The ANOVA was not significant for any of the survey items, therefore a Post hoc comparison (Bonferroni) was not needed to determine group differences. The results allow for the rejection of $\mathrm{H}_{3}$, which stated that there would be differences among faculty responses based on prior work experience in the sport industry. This finding is not necessarily consistent with the literature, which suggests that industry practitioners in hiring positions have, at times, questioned the value of a sport management degree. They argue that students in sport management programs don't get enough real-world experience or practice prior to entering the field, resulting in a preference to hire someone with experience over a sport management degree (Cuban, 2014; Dolich, 2004; King, 2009). Their unfavorable views towards sport management programs would suggest that faculty do not value the same types of experiential learning opportunities, however, this finding suggests the opposite, that regardless of whether or not faculty have prior work experience in the industry, favorable attitudes towards experiential learning exist across the board. Whether or not these attitudes translate to actual usage is still in question, but this particular finding supports the overall hypothesis for research question two, which predicted that faculty would have generally favorable attitudes towards experiential learning and its ability to aide student learning.

\section{Significance of the Study}

The results of this particular study could be significant for several key stakeholder groups. Sport management program directors, faculty, students, sport industry practitioners, as well as those professionals working to set COSMA curricular standards, 
could all benefit from an increased knowledge of how sport management faculty are using experiential learning techniques. In recent years, the academic field of sport management appears to have shifted toward a more applied approach to teaching and learning, but up until this study, a research gap remained in regards to the extent to which experiential learning practices are actually being implemented by faculty within these programs. The results of this particular study provide stakeholders with answers to many of those questions; in some ways confirming existing literature and other ways offering new insights into the application and attitudes towards the various experiential learning techniques.

The findings of this study may help sport management program directors to identify a future model for curriculum design that involves more opportunities for experiential learning. The following are some potential guidelines for sport management programs and faculty as they consider ways to incorporate more experiential learning into their curriculum. As evidenced here and in prior studies, (King, 2009; Petersen \& Pierce, 2009; Stier \& Schneider, 2000) sport management programs are still not implementing apprenticeship programs at high rates, despite mounting pressure from industry practitioners to provide students with more opportunities to develop key skills. Program directors and/or internship coordinators should work closely with their sites to identify specific training workshops, where students visit a sport organization for a week at a time and work on developing a key skill related to that particular site. These workshops could serve as an interim experience between the practicum elective early on and the culminating internship, and if possible be tied to a rotating topics course. These 
workshops could in turn benefit the sport practitioner and site, as these students would then be better prepared to later complete an internship experience at their site.

The findings in this study also suggest that volunteer exploration is not as widely adopted as it once was (Bennett, Henson, \& Drane, 2003; Valerius, et al., 1998). Program directors within sport management programs should consider adding a servicebased component to introductory sport management courses, which are often taken early in the student's degree audit. This would provide them with early exposure to a sport organization, while also giving them the benefits of completing a service-based project and allowing them to further connect with other students in their program and within the community. If a capstone course is implemented in the curriculum, a second servicebased component could be added so that students have another opportunity for volunteer exploration, this one coming at the end of their college experience. These two volunteer experiences would, in theory, bookend their college experience and allow for the full application of Kolb's experiential learning theory (ELT).

Another recommendation for program directors in particular, moving forward, is to insure that faculty are given adequate time and resources to implement experiential learning experiences for students. As the findings suggest, faculty with a light teaching load were more like to agree with the statement, "I do not have the resources to implement experiential learning opportunities." While $58.8 \%$ of faculty said they either Strongly Disagreed/Disagreed with this statement, $27.2 \%$ of faculty said they either Agreed or Strongly Agreed with the statement. This suggests that perhaps there is some variance in the number of resources or support available to faculty in developing experiential learning opportunities. Moving forward, directors could work with 
University teaching and learning departments to facilitate faculty training workshops, in which faculty learn more about experiential learning and are able to actually develop experiential practices and apply them.

Exploration into the results of this study could also allow faculty to reflect on their own teaching practices, and consider what others are doing to incorporate experiential learning techniques. Current and future sport management students could benefit from the findings of this study, as they could become more aware of the experiential learning practices occurring within their academic field and thus take better advantage of those opportunities offered on their campus. Sport industry practitioners who seek to hire graduates with more applied experience may be specifically interested in this key finding within the study. Finally, the results may also help program directors within doctoral programs to identify a need for increased training of sport management doctoral students in the area of pedagogy and curriculum design.

The results of this study also have the potential to add to the greater, ongoing debate within the field of sport management regarding the purpose of a sport management education. Is that purpose to provide a theoretical or applied education? Is it a combination of both? The results of this study provide a widespread analysis of experiential learning across sport management faculty, and in many ways confirm the literature that suggests that the field itself has moved towards a more applied and experiential framework.

\section{Limitations of the Study}

As with any research study, there are limitations to the present study. Because no instrument currently exists in sport management literature to measure experiential 
learning techniques, the survey instrument for the present study was adapted from an original survey utilized to gather information across another discipline, marketing. While the instrument was carefully adapted to include sport management constructs found in the literature, this could still be seen as a limitation in regards to testing validity.

Another potential limitation of this study is that by seeking participation from individual faculty as opposed to program directors, who represent an entire program, some results may be skewed based on the faculty member's role in the department. As addressed in the discussion above, not all faculty serve as field experience supervisors or internship coordinators, therefore not all faculty have the same opportunities to apply each of the experiential learning techniques. Similarly, the results of this study can not necessarily be generalized to reflect sport management programs across the board, as individual faculty usage is not necessarily reflective of that program as a whole.

Another limitation of this study is the low response rate, which limits the ability to generalize findings. Even though the researcher included a large potential pool of participants in the sample, an e-mail survey lacks a personal element, and is likely to get lost in many faculty member's e-mail inboxes. While once considered a novel concept, inspiring high response rates, in recent years, response rates for surveys administered online have decreased dramatically (Munoz-Leiva, Sanchez-Fernandez, Montoro-Rios, 2010). In fact, when compared to other more traditional modes of survey research, response rates have been estimated to be around $11 \%$ lower for internet surveys (Manfreda, Bosnjak, Berzelak, Haas, \& Vehovar, 2008). Also, by utilizing the NASSM list-serv, a subscription e-mail service with subscribers made up of both faculty and sport industry practitioners, the pool of potential respondents includes non-faculty. In order to 
avoid sampling error, any survey respondent who did not select a faculty classification in question 8 of the survey was removed from the data analysis.

While the present study produces a descriptive analysis of faculty usage of experiential learning techniques, and describes group differences based on faculty backgrounds, utilizing survey methodology limits the researcher's ability to gather indepth information about the participants. Now that a cursory explanation of experiential learning technique usage has been provided, perhaps a qualitative or mixed methods study would be appropriate to further develop this area of study. Further, the current study is limited in that it only asks faculty to select the categories of experiential learning techniques they use, not specific examples. Particularly for classroom-based experiential learning, it would have been beneficial to see which specific techniques are being utilized by faculty.

\section{Future Research Questions}

While this study provides answers to a variety of research questions related to the experiential learning practices and attitudes of sport management faculty, it has also implored the researcher to consider many new questions related to this growing content area. The following recommendations are suggested for further study.

After reviewing the results of this study that relate specifically to volunteer exploration, it is evident that additional research is needed to understand why usage rates and attitudes towards volunteer exploration or service learning are low. This finding was not consistent with the literature, which suggested that volunteer exploration, and/or service learning, is widely adopted across both institutions of higher learning (Sax \& Astin, 1997) and sport management programs specifically (Bennett, Henson, \& Drane, 
2003; Valerius, et al., 1998). Perhaps most interesting is the fact that, nearly a quarter (23.5\%) of respondents identified as "Triers", which means they have tried the technique once or twice in the past, but are not currently implementing it. This finding lends itself to a series of new research questions: Why are sport management faculty no longer using volunteer exploration at high rates and why are faculty who utilize it once or twice no longer interested in implementing it?

Another direction for future research relates to the support or lack of support faculty receive at both institutional and program levels, in relation to implementing experiential learning techniques. One finding specific to this study was that faculty with light teaching loads (1-2 courses per semester) are more inclined to agree with the statement, "I do not have the resources to implement experiential learning opportunities" than their counterparts with a heavy teaching load who teach $3+$ courses per semester. This finding brings up relevant questions related to the level of support faculty receive in actually implementing experiential learning techniques, both at the program level and at the institutional level. The literature suggests that experiential learning practices have been encouraged by higher education administrators, particularly due to contemporary research that suggests that student exposure to experiential education positively impacts student learning outcomes, as well as persistence and retention rates (Eyler, 2009; Pierson \& Troppe, 2010; The National Center for Public Policy and Higher Education, 2008), but encouragement does not necessarily equal actual support or resource allocation. An indepth content analysis of the teaching and learning services provided by Universities housing sport management programs could provide more information in this area. 
Another possible line of future research that could be derived from this study would be to begin assessing specific classroom-based experiential learning methods that are being implemented by sport management faculty. Results of this study revealed that over $80 \%$ of faculty are implementing some kind of classroom-based experiential learning technique currently, however, this study didn't seek to understand which methods were specifically being utilized. This information could be discovered in a variety of ways. A content analysis of articles related to classroom-based experiential that have been published in the Sport Management Education Journal throughout the last decade could provide a survey of information related to which specific methods are being utilized within individual classrooms. Once that study is complete, a new survey instrument could be developed based on the findings of the prior study, in order to assess more widespread application of the various in-class experiential methods. This survey could be sent to sport management faculty in order to provide more generalizable results.

Finally, one other direction for future research could be to examine the student's exposure to experiential learning opportunities throughout their sport management degree program, as well as their perceptions of those experiences. While it is beneficial to have the faculty perspective on how experiential learning is being implemented into the curriculum, it is arguably more important to examine the student's perspective on the various experiential learning techniques. The Experiential Learning in Sport Management survey instrument used in this study could be adapted in order to gauge student application and attitudes towards Foster and Dollar's (2010) five experiential learning techniques. Another option would be to conduct a longitudinal study that follows sport management students from their time as a student into the first 3-5 years of their career in 
the sport industry. This would allow for both the student view and the sport industry practitioner view, as well as the ability to analyze any changes that occur in regards to their attitude toward experiential learning once they enter the field as practitioners. 


\section{REFERENCES}

Amis, J., \& Silk, M. (2005). Rupture: promoting critical and innovative approaches to the study of sport management. Journal of Sport Management, 19, 355-366.

Andreasen, A.R. (1995). Marketing social change: Changing behaviour to promote health, social development, and the environment. San Francisco, CA: Jossey Bass.

Andrew, D.P.S., Pedersen, P., \& McEvoy, C. (2011). Research methods and design in sport management. Champaign, IL: Human Kinetics.

Ary, D., Jacobs, L.C., Razavieh, A., \& Sorensen, C. (2006).

Introduction to research in education (7th ed). Belmont, CA: Thomson \& Wadsworth.

Barr, R.B., \& Tagg, J. (1995). From teaching to learning: A new paradigm for undergraduate education. Change Magazine, 27(6), 12-25.

Bell, J.A., \& Countiss, J.R. (1993). Professional service through sport management internships. Journal of Physical Education, Recreation and Dance, 64(7), 45-48.

Bennett, G., Henson, R., \& Drane, D. (2003). Student experiences with service learning in a sport management class. Journal of Experiential Education, 26(2), 61-69.

Benson, L., Harkavy, I., \& Puckett, J. (2007). Dewey's Dream: Universities and Democracies in an Age of Education Reform. Philadelphia, PA: Temple University Press. 
Bower, G. G. (2013). Utilizing Kolb's experiential learning theory to implement a golf scramble. International Journal of Sport Management, Recreation, \& Tourism, 12, 29-56.

Bowers, M., Green, C., \& Seifried, C.S. (2014). Let the marketplace be the judge: NASSM founders reflect on the origins and trajectory of sport management. Journal of Sport Management, 28, 565-587.

Brassie, P.S. (1989). A student buyer's guide to sport management programs. Journal of Physical Education, Recreation and Dance, 60(9), 25-28.

Bush, L. (2009). Student public relations agencies: A qualitative study of the pedagogical benefits, risks, and a framework for success. Journalism and Mass Communication Educator, 64(1), 27-38.

Case Studies in Sport Management (CCSM) (2016). Mission statement. Retrieved from http://journals.humankinetics.com/cssm-mission-statement.

Cawley, R. (1999). Get to work, then get a career. SportsBusiness Journal, 2(33), 21, 34.

COSMA (2016). Understanding Accreditation. Retrieved from http://www. http://www. cosmaweb.org/AccredPrograms.

Cuban, M. (2014, February 23). Re: My 2 cents on sports marketing and what I learned from SMU basketball this week. Retrieved from http://blogmaverick.com/2014/02/23/my-2-cents-on-sports-marketing-and-what-ilearned-from-smu-basketball-this-week/.

Cuneen, J., \& Parks, J.B. (1997). Should we serve sport management practice or sport management education? A response to Weese's perspective. Journal of Sport Management, 11, 125-132. 
Cuneen, J. \& Sidwell, M.J. (2003). Sport management field experiences. Morgantown, WV: Fitness Information Technology.

DeLuca, J.R. \& Braunstein-Minkove, J. (2016). An evaluation of sport management student preparedness: Recommendations for adapting curriculum to meet industry needs. Sport Management Education Journal, 10, 1-12.

Desensi, J.T., Kelly, D.R., Blanton, M.D., \& Beitel, P.A. (1990). Sport management curricular evaluation and needs assessment: A multifaceted approach. Journal of Sport Management, 4, 31-58.

Dewey, J. (1916) Democracy and education: An introduction to the philosophy of education. New York, NY: Free Press.

Dolich, A. (2004, November). Speech at the annual meeting of Sport Marketing Association, Memphis, TN.

Eagleman, A.N., \& McNary, E.L. (2010). What are we teaching our students? A descriptive examination of the current status of undergraduate sport management curriculum in the United States. Sport Management Education Journal, 4(1), 117.

Eyler, J. (2009). The power of experiential education. Liberal Education, 95(4), 24-31.

Ferris, G.R., \& Perrewe, P.L. (2014). Development of sport management scholars through sequential experiential mentoring: Apprenticeship concepts in the professional training and development of academics. Sport Management Education Journal, 8(1), 71-74.

Foster, S.B., \& Dollar, J.E. (2010). Experiential learning in sport management: Internships and beyond. Morgantown, WV: Sheridan Books. 
Foster, S., Schwarz, E., \& Hatlem, P. (2009, May). The Foster five-step process: An inclusive sport management experiential learning model. Paper presented at North American Society for Sport Management conference, Columbia, SC. Abstract retrieved from http://www.nassm.com/files/conf_abstracts/2009-137.pdf

Frankel, J.R., \& Wallen, N.E. (2003). How to design and evaluate research in education. $5^{\text {th }}$ ed. New York, NY: McGraw-Hill.

Frisby, W. (2005). The good, the bad, and the ugly: Critical sport management research. Journal of Sport Management, 19, 1-12.

Geurin-Eagleman, A.N. \& McNary, E. (2014). The changing climates of the sport management academic job market and doctoral students' career expectations. Sport Management Education Journal, 8(1), 1-13.

Gleason, T. (1986). Sport administration degrees: Growing to fill a need/supply overwhelms demand. Athletic Administration (February), pp. 10-11.

Haeg, C. G., \& Lindstrom, M.J., (2010). Getting Potomac fever: Increasing civic engagement through experiential learning communities. Political Science Faculty Publications, 13.

Hardy, S. (1986). Sport management curriculums: The need for a business orientation. Unpublished report, Robert Morris College.

Heitner, D. (2015, October 19). Sports industry to reach $\$ 73.5$ billion by 2019. Forbes.

Helyar, J. (2006, September 16). Failing effort: Are universities'sports-management programs a ticket to a great job? Not likely. Wall Street Journal, R5. 
Hoffmann \& Michel (2010). Recognizing prior learning assessment best practices for evaluators: An experiential learning approach. The Journal of Continuing Higher Education, 58 (2), 113-120.

Hunter, R.J. \& Mayo, A. M. (1999). Issues in antitrust, the NCAA, and sports management. Marquette Sports Law Review, 10(1), 69-85.

Irwin, R.L., Southall, R.M., \& Sutton, W.A. (2007). Pentagon of sport sales training: A $21^{\text {st }}$ century sport sales training model. Sport Management Education Journal, l(1), 18-39.

Irwin, R., Sutton, W., \& McCarthy, L. (2008) Sport Promotion and Sales Management. $2^{\text {nd }}$ edition. Human Kinetics Publishers.

Itin, C. M. (1999). Reasserting the philosophy of experiential education as a vehicle for change in the 21st century. The Journal of Physical Education 22(2), 91-98.

Jones, D., Brooks, D., \& Mak, J.(2008). Examining Sport Management Programs in the United States. Sport Management Review, 11(1), 77-91.

King, B. (2009, August 23). New lessons to learn. Sports Business Journal. Retrieved from http://www.sportsbusinessdaily.com.

Kliebard, H. M. (2004). The struggle for the American curriculum, 1893-1958. New York, NY: RutledgeFalmer.

Kolb, D. A. (1984). Experiential learning: Experience as the source of learning and development. Upper Saddle River, NJ: Prentice Hall.

Kolb, A., \& Kolb, D. A. (2009). The learning way: Meta-cognitive aspects of experiential learning. Simulation Gaming, 40, 297-327. 
Kuh, G.D. 2008. High-impact educational practices: What they are, who has access to them, and why they matter. Washington, DC: AAC\&U.

Lebel, K., Danylchuk, K., \& Millar, P. (2015). Social media as a learning tool: An investigation of sport management faculty perceptions of digital pedagogies. Sport Management Education Journal, 9, 39-50.

Lewuis, L.H., \& Williams, C.J. (1994). Experiential learning: Past and present. New Directions for Adult and Continuing Education, 1994(62), 5-16.

Lynton, E. (1983). A crisis of purpose: Reexamining the role of the university. Change, $15,18-23,53$.

Mahony, D.F., \& Pitts, B.G. (1998). Research outlets in sport marketing: The need for increased specialization. Journal of Sport Management, 12(4), 259-272.

Major League Soccer National Sales Center. About us. Retrieved from: http://www.mlssoccer.com/nationalsalescenter/about.

Manfreda, K.M., Bosnjak, J., Berzelak, I., Haas \& Vehovar, V. (2008). Web surveys versus other survey modes: A meta-analysis comparing response rates. International Journal of Market Research 50(1): 79-104.

Mangold, K. (2007). Educating a new generation: teaching baby boomer faculty about millennial students. Nurse Educator, 32(1), 21-23.

Masteralexis, L.P., Barr, C.A., \& Hums, M.A. (1998). Principles and Practice of Sport Management, $5^{\text {th }}$ Ed. Boston, MA: Jones \& Bartlett Publishers.

McIntyre, F. S., Webb, D. J., \& Hite, R. E. (2005). Service learning in the marketing curriculum: faculty views and participation. Marketing Education Review, 15(1), $35-45$. 
McKelvey, S. \& Southall, R.M. (2008). Teaching sport sponsorship sales through experiential learning. International Journal of Sport Management and Marketing, $4(2 / 3), 225-242$.

McManus, D.A. (2005). Leaving the lectern: Cooperative learning and the critical first days of students working in groups. San Francisco, CA: Jossey-Bass.

Miller, T.W. (2001). Make the call: Online results are mixed bag. Marketing News, 35(20), 30-35.

Miller, J., Meaney, K.S., \& Podlog, L. (2012). Enhancing sport marketing research service-learning using Kolb’s experiential education model. International Journal of Sport Management, 13, 23-42.

Mintzberg, H. (1982). If you're not serving Bill and Barbara, then you're not serving leadership. In J.G. Hunt, U. Sekaran, \& C.A Schriesheim (Eds.), Leadership: Beyond established views. Carbondale, IL: Southern Illinois University Press.

Munoz-Leiva, R., Sánchez-Fernández, J., Montoro-Rios, R., Ibáñez-Zapata, J. (2010). Improving the response rate and quality in web-based surveys through the personalization and frequency of reminder mailings. Quality and Quantity, 44(5), 1037-1052.

NASPE-NASSM Joint Task Force on Sport Management Curriculum and Accreditation. (1993). Standards for curriculum and voluntary accreditation of sport management education programs. Journal of Sport Management, 7, 159-170.

NASSM. (2016). Sport management programs: United States. Retrieved from http://www.nassm.com/InfoAbout/Sport-MgmtPrograms/United_States. 
Newman, J. I. (2014). Sport without management. Journal of Sport Management, 28(6), 603-615.

Pauline, G. (2013). Engaging Students Beyond Just the Experience: Integrating Reflection Learning Into Sport Event Management. Sport Management Education Journal (Human Kinetics), 7(1), 1.

Pauline, G., \& Pauline, J.S. (2008). Teaching sport sponsorship activation through a client-based experiential learning project. Sport Management Education Journal, 2, 19-37.

Parkhouse, B.L. (1984). Shaping up to climb a new corporate ladder... Sport management. Journal of Physical Education, Recreation and Dance, 55, 12-14.

Parkhouse, B.L. (1987). Sport management curricula: Current status and design implications for future development. Journal of Sport Management, 1, 93-115.

Parkhouse, B. L. (2001). The management of sport: Its foundation and application (3rd ed.). New York, NY: McGraw Hill.

Petersen, J.C. \& Pierce, D.A. (2009). Professional sport league assessment of sport management curriculum. Sport Management Education Journal, 3(1), 107-121.

Pierce, D.A. \& Peterson, J.C. (2015). Integrating an experiential client-based ticket sales center into a sport sales course. Sport Management Education Journal, 9(1), 6672.

Pierce, D.A., Petersen, J.C., \& Meadows, B. (2011). Authentic assessment of experiential learning in sport sales. Sport Marketing Quarterly, 20, 75-83.

Pierson, M., \& Troppe, M. (2010). Curriculum to career. Peer Review, 12, 12-14. 
Pitts, B., \& Stotlar, D., (2007). Fundamentals of sport marketing (3 $3^{\text {rd }}$ ed.). Morgantown, WV: Fitness Information Technology.

Popp, N., \& McEvoy, C. D. (2010, November 1). True partnership takes sport management out of classroom. SportsBusiness Journal.

Rhoads, R.A. (1997). Community service and higher learning: Explorations of the caring self. Albany, NY: State University of New York Press.

Rogers, C. R. (1983). Freedom to learn for the 80s. Columbus, OH: Charles E. Merrill.

Sawyer, T.H. (1993). Sport management: Where should it be housed? Journal of Physical Education, Recreation, and Dance, 64(9), 4-5.

Sax, L. \& Astin, A. (1997). The benefits of service: Evidence from undergraduates. Educational Record, 78, 25-32.

Schneider, R.C., \& Stier, W.F. (2006). Sport management field experiences as experiential learning: Ensuring beneficial outcomes and preventing exploration. The Sport Management and Related Topics Journal, 2(2), 36-43.

Southall, R.M., Nagel, M.S., LeGrande, D.J., \& Han, P. (2003). Sport management practitca: A metadiscrete experiential learning model. Sport Marketing Quarterly, 12(1), 27-36.

Spence, K. K., Hess, D. G., McDonald, M., \& Sheehan, B. J. (2009). Designing experiential learning curricula to develop future sport leaders. Sport Management Education Journal, 3(1), 1-25.

Sport Management Education Journal (2016). Retrieved from: http://journals.humankinetics.com/smej. 
Sport Management Program Review Council (2000). Sport Management Program Standards and Review Protocol. Oxon Hill, MD: AAHPERD Publications. Stanek, J.M. (2010). Athletic training education: are programs teaching students the skills of evidence based practice? (Doctoral dissertation). Retrieved from ProQuestDissertations and Theses. (Order No. 3424374, Illinois State University).

Stanton, T., \& Ali, K. (1987). The experienced hand: A student manual for making the most of an internship (2nd ed.). Cranston, RI: Carroll Press.

Sutton, W. A. (1989). The role of internships in sport management curricula--A model for development. Journal of Physical Education, Recreation and Dance, 60(7), 20-24.

Tanner, D., \& Tanner, L. N. (1980). Curriculum development: Theory into practice (2nd ed.). New York, NY: Macmillan.

Taylor, M. S. (1998). Effects of college internships on individual participants. Journal of Applied Psychology, 73(3), 393-401.

The National Center for Public Policy and Higher Education (2008). Measuring up 2008: The national report card on higher education. Retrieved from: http://measuringup2008.highereducation.org/print/NCPPHEMUNationalRpt.pdf.

Turesky, E. F., \& Gallagher, D. (2011). Know thyself: Coaching for leadership using Kolb's experiential learning theory. The Coaching Psychologist, 7(1), 5-14.

Valerius, L., Keller, M. J., Doyle, E. I., \& Collins, J. R. (1998). Inclusion of diversity in leisure services curricula. Schole: A Journal of Leisure Studies and Recreation Education. 14, 45-61. 
Weese, W.J. (1995). If we're not serving practitioners, then we're not serving sport management. Journal of Sport Management, 9, 237-243.

Wilson, L.S. (2008). Examining technology utilization in sport management curricula and teaching (Doctoral dissertation) Available from Proquest Dissertation \& Theses database. (UMI No. 3324110) 2008.

You, Z. \& Rud, A. G. (2010). A model of Dewey's moral imagination for service learning: Theoretical explorations and implications for practice in higher education. Education and Culture, 26(2), 36-51.

Zakus, D.H., Malloy, D.C., \& Edwards, A. (2007). Critical and ethical thinking in sport management: Philosophical rationales and examples of methods. Sport Management Review, 10, 133-158.

Ziegler, E.F. (1994). Critical thinking for the professions of health, sport, \& physical education, recreation, and dance. Champaign, IL: Stipe 
APPENDIX A

\section{PERMISSION TO MODIFY SERVICE LEARNING IN}

\section{MARKETING CURRICULUM SURVEY}




\section{Survey tool: Service Learning in the Marketing Classroom: Faculty Views and Participation}

Sattler, Elizabeth <sattlerelizabetha@sau.edu> To: fmcintyre@westga.edu, dwebb@westga.edu

Dr. McIntyre \& Dr. Webb,

Hello! My name is Liz Sattler and I am a doctoral student at Illinois State University. I am in the early stages of my dissertation work and in my readings I came across your article, "Service Leaming in the Marketing Classroom: Faculty Views and Participation". In my dissertation, I plan to study sport management faculty views/participation of experiential learning. I think the survey tool you developed for your study might be able to be adapted for my study. Would you be willing to share your survey tool for my adaption? Of course I would reference your study and the survey tool in my dissertation.

Please let me know if you have any questions!

Thanks for your time!

\section{Liz Sattler}

Instructor

Department of Kinesiology

St. Ambrose University

518 W Locust St

Davenport, IA 52803

230 Hayes Hall

$\mathrm{Ph}:$ 562-333-6234

Faye McIntyre <fmcintyr@westga.edu>

Thu, Sep 10, 2015 at 3:34 PM

To: "Sattler, Elizabeth" <sattlerelizabetha@sau.edu>

Hello Elizabeth.

I have attached the survey and cover letter used for our research. I hope it helps you, and good luck in your studies!

Best,

Faye

From: Sattler, Elizabeth [mailto:sattlerelizabetha@sau.edu]

Sent: Thursday, September 10, 2015 2:33 PM

To: fmcintyre@westga.edu; dwebb@westga.edu

Subject: Survey tool: Service Learning in the Marketing Classroom: Faculty Views and Participation

[Quoted text hidden]

2 attachments

(i) Service learning letter.doc

$40 \mathrm{~K}$

可 Service Learning.doc

$308 \mathrm{~K}$ 
APPENDIX B

E-MAIL COMMUNICATION TO NASSM LISTSERV

TO REQUEST PARTICIPATION 


\title{
Experiential Learning in Sport Management Survey
}

\author{
1 message
}

Sattler, Elizabeth <sattlerelizabetha@sau.edu>

Fri, Dec 11, 2015 at 10:38 AM

To: SPORTMGT@unb.ca

Hello!

My name is Liz Sattler and I am currently a doctoral student at Illinois State University. For my dissertation, I am conducting a study on the experiential leaming practices of sport management faculty members. In order to gather relevant data, I am writing to you to request your participation in a brief survey. If you are currently teaching in a sport management program or have taught sport management courses in the past, I want to hear from you (this includes adjunct faculty and doctoral students with teaching experience).

If you choose to participate in this study, you will be asked to take part in an online survey. The survey will be made available to you via the link at the bottom of this e-mail. The survey should take you no longer than 10-15 minutes to complete.

I realize this is a very busy time of year for many, so as a thank you for your time and input, participants who complete the survey instrument will be entered into a drawing for one of two (2) $\$ 50$ Visa gift cards.

Your participation in the survey is completely voluntary and all of your responses will be kept confidential. Thank you very much for your time and cooperation. If you have any questions regarding the study, feel free to contact me.

Survey link: https://wmw. surveymonkey.com/r/53DXJZG

Best,

Liz Sattler

Department of Kinesiology

St. Ambrose University

518 W Locust St

Davenport, IA 52803

230 Hayes Hall

Ph: 562-333-6234 


\section{APPENDIX C}

EXPERIENTIAL LEARNING IN SPORT MANAGEMENT (ELSM) SURVEY INSTRUMENT 
Welcome to My Survey: Experiential Learning In Sport Management

Thank you for considering participation in this survey! The survey should take you no longer than 10-15 minutes to complete. You can complete the survey from anywhere and at a time that is convenient for you. The completion of the online survey is the extent to your participation in this study.

Risks and Discomforts

The risks associated with the proposed study are minimal. As with most teaching-related surveys, participants may experience minimal psychological discomfort in providing information about their own teaching practices. Additionally, participants may experience minimal inconvenience in taking part in the survey as participation will temporally remove them from their normal day-to-day activities. Finally, as with most studies, there is a risk that participants will lose their confidentiality.

Possible Benefits

There are minimal direct benefits to the participants in this study. They may experience satisfaction in assisting a doctoral student complete work towards their dissertation, and to better understand how experiential learning is applied in sport management. Further, the act of reflecting on their own teaching experience may help them become more aware of their own practices in the classroom.

Protection of Privacy and Confidentiality

Special care will be taken in maintaining the confidentiality of the participants during all stages of the research project. The researchers will do everything possible to protect your privacy and confidentiality. While the respondents responses are confidential, their identities and responses will not be anonymous as each respondent will be required to provide an e-mail address if they wish to be included in the drawing for the Visa Gift cards. Participants should rest assured that their e-mail address will never be linked to their responses and that their confidentiality will be kept in-tact. The data gathered from the survey responses will only be used in aggregate. Specific security measures will be taken to ensure your identify is not breached at any point in the data collection and analysis process.

Choosing to Be in the Study

You do not have to be in this study. You may choose not to take part and you may choose to stop taking part at any time. There are no right or wrong answers to any survey questions and your participation or lack-there-of will have no impact outside of this study; and you may withdraw from the study at any time without penalty. If you choose to stop taking part in this study, the information you have already provided will be used in a confidential manner or will be destroyed immediately, as you choose. Withdrawal from the study will not result in any loss of benefit to the respondent.

Contact Information

If you have any questions or concerns about this study or if any problems arise, please contact Liz Sattler at St. Ambrose University at 309-231-6160.

If you have any questions or concerns about your rights in this research study please contact the Illinois State University Research Ethics and Compliance Office at 309-438-2529 or rec@ilstu.edu.

By clicking "Agree" button below you are indicating that you are at least 18 years old, have read and understood this consent form and agree to participate in this research study. Please print a copy of this page for your records. 
Experiential learning is defined as a method of learning where students gain knowledge through observation and interaction with situations or experiences, as opposed to traditional learning, where students learn through reading, lecture, and/or testing (Itin, 1999). For the purposes of this study, student learning will refer to the student's ability to connect and apply concepts through the use of experiential learning methods.

* 1. For each of the following experiential learning methods, please indicate your level of involvement as an instructor, based on the scale below:

$\begin{array}{ll}1 & \text { I have never used this method } \\ 2 & \text { I am considering this for the near future } \\ 3 & \text { I have used this once or twice } \\ 4 & \text { I use this on a regular, ongoing basis } \\ 5 & \text { I have used this in the past but do not plan to use it in the future }\end{array}$

\begin{tabular}{|c|c|c|c|c|c|}
\hline & 1 & 2 & 3 & 4 & 5 \\
\hline $\begin{array}{l}\text { Volunteer Exploration: } \\
\text { Students complete some } \\
\text { kind of unstructured, } \\
\text { volunteer experience where } \\
\text { they provide hours of their } \\
\text { time in order to assist a } \\
\text { local organization as well } \\
\text { as to gain experience in } \\
\text { some area of the sport } \\
\text { management field. }\end{array}$ & & & & & \\
\hline $\begin{array}{l}\text { Apprenticeship: Students } \\
\text { complete a formal entry } \\
\text { level work experience that } \\
\text { involves observation and } \\
\text { instruction from masters, } \\
\text { guided practice, and finally. } \\
\text { progression into } \\
\text { performance of tasks that } \\
\text { ultimately leads to } \\
\text { independent work by the } \\
\text { learne }\end{array}$ & & & & & \\
\hline $\begin{array}{l}\text { Classroom: Students } \\
\text { participate in experiential } \\
\text { learning activities in the } \\
\text { classroom. Examples } \\
\text { include role playing, case } \\
\text { study, guest speakers, } \\
\text { client-based projects, and } \\
\text { other simulations. }\end{array}$ & & & & & \\
\hline $\begin{array}{l}\text { Practicum Elective: } \\
\text { Students gain additional } \\
\text { experience in the sport } \\
\text { management field through } \\
\text { a formal practicum } \\
\text { experience, typically } \\
\text { involving anywhere from } 5 \text { - } \\
20 \text { hours a week. }\end{array}$ & & & & & \\
\hline $\begin{array}{l}\text { Culminating Internship: } \\
\text { Students complete a } \\
\text { comprehensive work } \\
\text { experience through either a } \\
\text { part-time or full-time } \\
\text { internship experience in the } \\
\text { sport management field. }\end{array}$ & & & & & \\
\hline
\end{tabular}


* 2. Of the experiential learning methods listed above, which would you rank as the most effective in aiding student learning?

Volunteer exploration

Apprenticeship

Classroom

Practicum elective

Intemship

Other (please specify)

(20)

* 3. After reading each statement below regarding experiential learning, indicate your level of disagreement or agreement by selecting the appropriate number on a 7-point Likert-scale. The rank of 1 indicates you strongly disagree with the statement, and 7 indicates that you strongly agree.

Experiential leaming teaches
students interpersonal skills.
Experiential leaming leads
students to see links
between theory and practice.
Experiential leaming teaches
students problem-solving
techniques.
Experiential leaming teaches
critical thinking skills.
I don't mind spending the
extra time to structure
experiential leaming
opportunities.
Experiential leaming
programs should be closely
tied to the curriculum.
Experiential leaming builds
relationships with local
businesses and
organizations.
I do not have the resources
to implement experiential
leaming opportunities.


The following section asks for some background information on you, the course(s) you teach, and the program in which you teach.

* 4. Please specify your gender:

Female

Male

* 5. Please specify the number of years you've been teaching in sport management:

$1-2$

$3-5$

6-8

$9+$

* 6. What is the highest level of school you have completed or the highest degree you have received?

Bachelors degree

Masters degree

Ph. D

Ed. D

Other (please specify)

(2)

* 7. Which of the following describes your role in the department in which you currently work?

Department chair

Program director

Faculty member

Adjunct faculty member

Doctoral student

Other (please specify) 
8. If you have a terminal degree, please specify the school or program from which you received your degree (Ex.: School of Business or Department of Education).

* 9. Please specify the number of years you worked full-time as a practitioner in the sport industry prior to becoming a faculty member.

$1-2$

$3-4$

5-6

$7-9$

$10+$

I have no prior full-time work experience in the sport industry

* 10. Please specify the number of sport management courses you teach per semester.

1

2

3

4

$5+$

I'm not currently teaching any sport management courses.

* 11. Please specify the sport management courses/areas you have taught in or currently teach in (check all that apply).

Socio-cultural dimensions of sport

Management and leadership of sport

Ethics in sport management

Marketing in sport

Communication in sport

Sport sales

Finance in sport

Legal aspects of sport

Govemance in sport

Professional preparation in sport management (ex.: field experiences)

Sport facility and event management

Other (please specify) 
* 12. The sport management program in which I teach is housed within the School or Department of

Business

Kinesiology

Education

Sport management

Other (please specify)

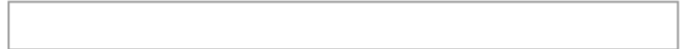

* 13. Is your sport management program accredited by the Commission on Sport Management Accreditation (COSMA)?

Yes

No

Undergraduate level only

Graduate level only

* 14. My institution follows the Commission on Sport Management Accreditation (COSMA) guidelines for curriculum development.

Y Yes

( No

I do not know

15. Please provide any additional feedback you wish to share relative to your experience using experiential learning methods.

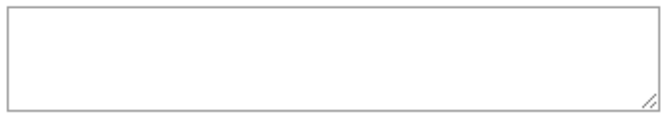

16. If you are interested in being entered into a drawing for one of the $\mathbf{2} \$ 50$ Visa Gift Cards, please provide your e-mail address. This information will not be associated with your survey responses and will only be used to contact you in the event you have been chosen as a winner of one of the gift cards.

Email Address 
APPENDIX D

INSTITUTIONAL REVIEW BOARD APPROVAL 


\title{
IRB Protocol 2015-0367: Examining the Application of Experiential Learning Techniques Across Sport Management Programs
}

\author{
Research Ethics \& Compliance <rec@ilstu.edu> \\ Tue 12/8/2015 3:45 PM \\ To:Crumpler, Thomas <tpcrump@ilstu.edu>; \\ Cc:Sattler, Liz <easatt!@ilstu.edu>; Hunt, Carolyn <cshunt@ilstu.edu>;
}

December 8, 2015

Thomas Crumpler

5330 Teaching and Learning

Thank you for submitting the IRB protocol titled "Examining the Application of Experiential Learning Techniques Across Sport Management Programs" for review by the Illinois State University Institutional Review Board (IRB). The IRB has reviewed this research protocol and effective 12/4/2015 has classified this protocol as Exempt from Further Review.

This protocol has been given the IRB number 2015-0367. This number should be used in all correspondence with the IRB.

This approval of this protocol is valid only for the research activities, timeline, and subjects described in the above named protocol. IRB policy requires that any changes to this protocol be reported to, and approved by, the IRB before being implemented. You are also required to inform the IRB immediately of any problems encountered that could adversely affect the health or welfare of the subjects in this study. Please contact Kathy Spence, Director of Research Ethics \& Compliance at 438-2520 or myself in the event of an emergency. All other correspondence and questions should be addressed to:

Institutional Review Board

Campus Box 3330

Hovey Hall, Room 307

Telephone: 438-2529

E-mail: rec@IllinoisState.edu

It is your responsibility to notify all co-investigators (Liz Sattler), including students, of the classification of this protocol as soon as possible. It is your responsibility to keep a copy of the approved protocol.

Thank you for your assistance, and the best of success with your research.

\author{
Alycia Hund, Chairperson \\ Institutional Review Board \\ Telephone: 438-2529 \\ cc: Carolyn Hunt, Department Rep, TCH
}

